This is a self-archived - parallel published version of this article in the publication archive of the University of Vaasa. It might differ from the original.

\title{
Performance and emission characterization of a common-rail compression-ignition engine fuelled with ternary mixtures of rapeseed oil, pyrolytic oil and diesel
}

Author(s): Mikulski, Maciej; Ambrosewicz-Walacik, Marta; Duda, Kamil; Hunicz, Jacek

Title: $\quad$ Performance and emission characterization of a common-rail compression-ignition engine fuelled with ternary mixtures of rapeseed oil, pyrolytic oil and diesel

Year: $\quad 2019$

Version: Accepted manuscript

Copyright Elsevier, Creative Commons Attribution Non-Commercial No Derivatives License

Please cite the original version:

Mikulski, M., Ambrosewicz-Walacik, M., Duda, K., \& Hunicz, J., (2019). Performance and emission characterization of a common-rail compression-ignition engine fuelled with ternary mixtures of rapeseed oil, pyrolytic oil and diesel. Renewable Energy Online October 31, 1-28. https://doi.org/10.1016/j.renene.2019.10.161 


\section{Journal Pre-proof}

Performance and emission characterization of a common-rail compression-ignition engine fuelled with ternary mixtures of rapeseed oil, pyrolytic oil and diesel

Maciej Mikulski, Marta Ambrosewicz-Walacik, Kamil Duda, Jacek Hunicz

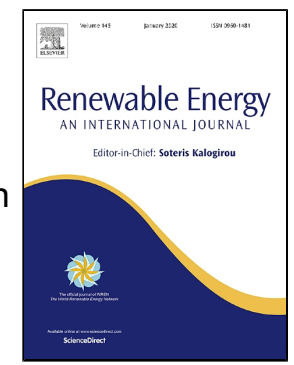

PII:

S0960-1481(19)31658-1

DOI:

https://doi.org/10.1016/j.renene.2019.10.161

Reference:

RENE 12530

To appear in:

Renewable Energy

Received Date:

04 March 2019

Accepted Date:

29 October 2019

Please cite this article as: Maciej Mikulski, Marta Ambrosewicz-Walacik, Kamil Duda, Jacek Hunicz, Performance and emission characterization of a common-rail compression-ignition engine fuelled with ternary mixtures of rapeseed oil, pyrolytic oil and diesel, Renewable Energy (2019), https://doi. org/10.1016/j.renene.2019.10.161

This is a PDF file of an article that has undergone enhancements after acceptance, such as the addition of a cover page and metadata, and formatting for readability, but it is not yet the definitive version of record. This version will undergo additional copyediting, typesetting and review before it is published in its final form, but we are providing this version to give early visibility of the article. Please note that, during the production process, errors may be discovered which could affect the content, and all legal disclaimers that apply to the journal pertain.

(c) 2019 Published by Elsevier. 


\title{
Performance and emission characterization of a common-rail compression-ignition engine fuelled with ternary mixtures of rapeseed oil, pyrolytic oil and diesel
}

\author{
Maciej Mikulski1,a, Marta Ambrosewicz-Walacik², Kamil Duda², Jacek Hunicz ${ }^{3}$ \\ ${ }^{1}$ School of Technology and Innovation, Energy Technology, University of Vaasa, Wolffintie 34,FI-65200 Vaasa, \\ Finland \\ ${ }^{2}$ Faculty of Technical Sciences, University of Warmia and Mazury in Olsztyn, Słoneczna 46A, 10-710 Olsztyn, Poland \\ ${ }^{3}$ Faculty of Mechanical Engineering, Lublin University of Technology, Nadbystrzycka 36, 20-618 Lublin, Poland \\ a Corresponding author, e-mail: maciej.mikulski@uwasa.fi
}

\begin{abstract}
Biofuels are one of the short-term alternatives for reducing the well-to-wheel greenhouse gas footprint of transport. In the framework of compression-ignition engine fuels. This study investigates the feasibility of using cold-pressed rapeseed oil as a biocomponent, admixed with distilled tyre pyrolytic oil, as an energy-efficient alternative to commonly considered methyl ester-based mixtures in diesel fuel. Selected ternary and binary fuel blends are subjected to engine tests. Their scope covers $80 \%$ of the engine map and aims at identifying tradeoffs between fuel composition, engine performance and emissions. The results show that fuel mixtures containing a large fraction of rapeseed oil (up to 55\% by volume) can be effectively combusted when pyrolytic oil distillate is introduced as the additive. The deterioration in brake efficiency for such fuel does not exceed $1.2 \%$ with respect to diesel baseline. At the same time, the results are superior in terms of both efficiency and emissions when compared to FAME-based biodiesel. Finally, with indicated efficiencies on a similar level as the diesel baseline, suggesting improved burning rate with pyrolytic oil addition, the study identifies parasitic losses in fuel injection equipment as a significant contributor to the overall efficiency penalty for the examined ternary mixtures.
\end{abstract}

Keywords: diesel engine; rapeseed oil; pyrolytic oil; waste tyres; efficiency analysis, exhaust emissions.

Nomenclature

$\mathrm{Bio}_{20}-\mathrm{DF}_{80} \quad$ binary blend of rapeseed methyl ester and diesel fuel $(20: 80, \mathrm{v} / \mathrm{v})$

BMEP brake mean effective pressure [bar]

BTE brake thermal efficiency [\%]

CA crank angle [deg]

$\mathrm{CI}$ compression ignition

$\mathrm{CO}$ carbon monoxide

$\mathrm{CO}_{2} \quad$ carbon dioxide

$\mathrm{COV}_{\text {IMEP }} \quad$ coefficient of variation in IMEP [\%]

DF diesel fuel

DMFTPO distilled medium fraction of pyrolytic oil

DR binary blend of diesel fuel and rapeseed oil

EGO exhaust gas opacity [\%]

EGR exhaust gas recirculation

FAME fatty acid methyl esters

$\mathrm{G}_{\text {air }} \quad$ air aspired to the engine $[\mathrm{kg} / \mathrm{h}]$

$\mathrm{G}_{\text {fuel }} \quad$ fuel consumption $[\mathrm{kg} / \mathrm{h}]$

HRR heat release rate $[\mathrm{J} / \mathrm{CA}]$

IMEP indicated mean effective pressure [bar] 


$\begin{array}{lll}21 & \text { JME } & \text { Jatropha methyl esters } \\ 22 & \text { LHV } & \text { lower heating value }[\mathrm{MJ}] \\ 23 & \text { N } & \text { engine rotational speed }[\mathrm{rpm}] \\ 24 & \text { NOx } & \text { total nitrogen oxides } \\ 25 & \text { PAH } & \text { polycyclic aromatic hydrocarbons } \\ 26 & \text { PM } & \text { particulate matter } \\ 27 & \text { pp } & \text { percentage point } \\ 28 & \text { RME } & \text { rapeseed methyl ester } \\ 29 & \text { RO } & \text { rapeseed oil } \\ 30 & \text { rpm } & \text { revolutions per minute } \\ 31 & \text { SOA } & \text { start of actuation [CA] } \\ 32 & \text { TDC } & \text { top dead center } \\ 33 & \text { Te } & \text { engine torque [Nm] } \\ 34 & \text { THC } & \text { total hydrocarbons } \\ 35 & \text { TPO } & \text { pyrolytic oil from waste car tyres } \\ 36 & \text { TPO1-TPO5 } & \text { ternary blends of diesel fuel, rapeseed oil and medium fraction of pyrolytic oil }\end{array}$

\section{Introduction}

The use of fossil resources has led to increased greenhouse gas emissions, adversely affecting the Earth's atmosphere. Over the past five decades, greenhouse gas emissions, mainly $\mathrm{CO}_{2}, \mathrm{CH}_{4}$ and $\mathrm{N}_{2} \mathrm{O}$, more than doubled, from $24.5 \mathrm{GtCO}_{2}$ eq/year in 1970 to $50.9 \mathrm{GtCO}_{2}$ eq/year in 2017 [1]. The presence of these gases in the atmosphere is one of the major causes of global warming and other climate changes. World Energy Resources Reports prepared by the World Energy Council since 1988 show that significant changes have occurred in global consumption of energy resources in the last 15 years. Intensive growth of energy production from renewable sources has led to new investments for the energy economy, as well as the development of technologies for obtaining and processing alternative materials [2].

Despite the recent rapid decline in the reputation of diesel engines, they will be in service for many years to come, particularly in the case of heavy-duty and industrial vehicles. When coupled with environmental and health concerns relating to climate change and air quality, it follows that it is necessary to shift towards balanced fuel sources including biofuels and waste fuels.

Alcohols are intensively investigated as potential candidates for feasible fuels that can reduce carbon footprint. Ethanol has already reached substantial market share as a gasoline admixture. Methanol, being low-carbon on a tank to wheel basis, with its wide-spread infrastructure, and scalability potential, is regaining attention as transport fuel [3, 4]. It can be inexpensively produced from fossil fuels, but also from, waste, biomaterials, or renewable electricity with recaptured atmospheric $\mathrm{CO}_{2}$. As far as the wide utilization of methanol in different combustion concepts goes, it is not directly applicable as a drop-in fuel in CI engines. However, small admixtures of methanol to diesel (up to 5-7 \%) can be used without hardware or control modifications, as soon as emulsion stabilization is concerned [3]. For actual and comprehensive review of methanol in internal combustion engine applications the reader is referred to the recent work by Verhelst et al. [4].

It is commonly known that use of oilseed-derived biofuels substantially reduces well-to-wheels greenhouse gas emissions. The most commonly considered drop-in alternative fuel for CI engines is biodiesel based on FAME. The effects of biodiesel on CI engine combustion and exhaust emissions are well understood. Combustion characteristics such as auto-ignition delay and combustion duration are quite similar. In terms of emissions, biodiesel fuels show reduced soot production but increased $\mathrm{NO}_{\mathrm{X}}$ emissions compared with $\mathrm{DF}$ [5]. Emissions from biodiesel fuels are widely investigated for the production of regulated toxic compounds: there are some drawbacks in terms of emissions of some unregulated species. For example, Koszalka et al. [6] performed a detailed exhaust gas analysis and demonstrated that combustion of biodiesel fuel causes increased emissions of aldehydes in comparison with mineral diesel fuel.

The overall environmental benefit of using biodiesel fuels depends greatly on their energy consumption, extraction and refining processes, so the ability to use raw organic materials directly in compression-ignition engines would seem to offer an intrinsic environmental advantage. Recently published studies emphasize the advantages of using crude vegetable oils but suggest using biodiesel as a fuel for compression-ignition engines has an adverse effect [7, 8, 9]. Studies by Estaban et al. [7] using methods known as life cycle impact assessment and energy return on investment, 
found that raw oils generate significantly lower well-to-wheel emissions than biodiesel, despite the fact that biodiesel's engine-specific emissions are similar or favorable. Similar conclusions were reached by Hossain and Davies [8]. Furthermore, the produced-to-consumed energy ratio turned out to be higher for raw oils. Ortner et al. [9] used life cycle assessment modelling to compare greenhouse gas emissions of pure and waste vegetable oil and the biodiesel produced from them. They concluded that processed vegetable oils generate the highest amounts of $\mathrm{CO}_{2}$ over the whole life cycle.

Summarizing the above considerations, it can be stated that unprocessed oils are renewable, biodegradable and characterized by low environmental impact. However, their physical properties, especially the high viscosity and cold filter plugging point of raw oils, prevent their use as standalone fuels. So the thesis underpinning this study is that the properties of raw vegetable oils and their mixtures with diesel fuel could be greatly improved by a meagre addition of distillated pyrolytic oils, forming a viable ternary blend. Such a fuel could combine environmental benefits with acceptable efficiency and operational characteristics.

The European Union is tending to lean towards a gradual phase-out of first generation biofuels, preferring instead advanced biodiesel from algae or cellulose and use of pyrolytic oils from waste products like plastics and rubbers [10, 11]. Each year around the world 1.5 billion of tyres are produced, corresponding to approximately $17 \mathrm{Mt}$ [12]. Waste tyres are very problematic for the environment, but can also provide some opportunities for resource conservation because they can be sources of valuable fuels, e.g. pyrolytic oils [13]. However, use of unprocessed pyrolytic oils, as with raw vegetable oils, is limited generally by their high viscosity, density and impurity content. The viscosity issue in particular concerns countries with a colder climate $[6,14,15]$. Other issues associated with the application of pyrolytic oils include their low flash point, which affects safety, and high sulphur content of oils that are produced from waste rubber, e.g. TPO $[16,18]$.

To make raw vegetable oils or pyrolytic oils feasible fuels for CI engines, some engine fueling system modifications or fuel treatment methods have been proposed. Ikura et al. [18] stated that oils produced by pyrolysis and intended for use as fuels in $\mathrm{CI}$ engines should be preheated or subjected to higher injection pressure. They also highlighted pyrolytic oils' inferior auto-ignition properties compared with DF. These shortcomings can be minimized when pyrolytic oils are used as additive to DF, but that in turn creates another difficulty associated with these liquids' poor miscibility. Bridgwater et al. [19] added alcohols such as ethanol and propanol to improve miscibility. Ikura et al. [18] suggested subjecting the mixture to emulsification. Such emulsions are, however, unstable and require the use of on-board ultrasound hemispheres or need to be chemically stabilised. Mulimani and Navindgi [20] examined emulsions of pyrolytic oil from de-oiled seed cake of the mahua (share from 10 to $40 \%, \mathrm{v} / \mathrm{v}$ ) with DF (share of 50 to $80 \%$, v/v), and additions of surfactant (Polysorbate 20,8\%,v/v) and diethyl ether (2\% v/v). Such a mixture enabled the creation of a stable emulsion.

Pyrolytic oil's applicability as a fuel component for a CI engine can further be constrained by combustion characteristics and the environmental impact of the exhaust gases. Mulimani and Navindgi [16] examined emission characteristics of a $\mathrm{CI}$ engine fueled with emulsions mentioned in the previous paragraph. The smoke emissions of emulsified fuel blends were lower in comparison with DF. The authors emphasized that the examined fuel mixtures were characterized by higher oxygen content compared to DF, which reduced soot formation. It was also observed that increasing the amount of emulsified TPO also elongated combustion duration, which in turn led to lower $\mathrm{NO}_{\mathrm{X}}$.

Murugan et al. [21] investigated combustion of fuel blends containing high fractions (from $10 \%$ to $50 \% \mathrm{v} / \mathrm{v}$ ) of TPO and DF. The research was performed on a single-cylinder CI engine with a mechanical fuel injection system. The HRR analysis showed that an increase in the TPO fraction delayed the high temperature reaction phase. This was attributed to higher viscosity and lower volatility of TPO. Consequently, the fuel fraction burned during the premixed combustion phase was higher. This ultimately gave a clear increase in peak pressure when increasing the TPO fraction. However, the large-scale additions of TPO to DF produced increased emissions of all exhaust gas toxic compounds and higher opacity. For a lower TPO content, the trends in emissions were less clear and dependent on engine load.

Frigo et al. [22] also investigated the effect of using fuel blends with high fractions ( 20 and $40 \%$, v/v) of TPO in mixtures with DF on a single-cylinder CI engine. The authors found that an increase in TPO content reduced THC emissions, but increased emissions of $\mathrm{CO}$ at high engine-loads. This trade-off resulted from elongated ignition delay, which ultimately was considered a limiting phenomenon for fuels with very high TPO contents. Hürdoğan et al. [23] investigated blends of DF with additions of $10 \%, 20 \%$ and $50 \%$ of TPO. The authors noted that the sample with the highest pyrolytic oil content was too viscous to allow attainment of the engine's rated performance. For the two other fuel blends, there were no meaningful changes in exhaust emissions with respect to pure DF. One exception was $\mathrm{NO}_{\mathrm{X}}$ emissions under high engine-load conditions, which decreased as the TPO fraction increased. Nevertheless, the authors 
concluded that a $10 \%$ addition of TPO in DF is an optimal composition in terms of efficiency and environmental impact.

Recently Uyumaz et al. [24] performed a detailed combustion analysis from single in-cylinder pressure measurements. The focus was on one particular fuel blend: 10\% TPO and 90\% DF. Significant reduction in combustion duration with TPO addition was correlated with a substantial increase in pressure rise rates. The calculated ringing index for the fuel blend was doubled when compared with DF. Additionally, the combustion of fuel with TPO was less stable in terms of cycle-to-cycle variability in IMEP.

It should be noted that the above-mentioned studies were performed on CI engines with mechanical fuel injection systems offering single fuel injection. Martínez et al. [25] performed tests on a modern engine with an electronically controlled, common-rail injection system. The engine was fueled with DF with 5\% TPO addition, and the experiments were conducted at a limited number of operating points, mainly partial load. The combustion of fuel containing TPO produced more smoke than DF under all tested operating conditions. The increased smoke was attributed to TPO's higher content of aromatic compounds, which were considered to be precursors for soot generation. The study's authors also cited the greater opacity was associated with a higher boiling point of the TPO sample and the presence of distillation residues in the fuel sample. Additionally, a detailed analysis of PM size distribution showed that TPO extensively promotes creation of small-size particles.

Recently Shahir et al. [26] investigated the performance and emission characteristics of a four-cylinder, commonrail direct injection CI engine operating with blends of TPO ranging from $10 \%$ to $50 \%$ with DF. The engine tests showed that the 30\% TPO mixture provided the best BTE. Emissions of $\mathrm{NO}_{\mathrm{X}}$ and unburned hydrocarbons increased with increasing the TPO fraction. In contradiction, Bodisco et al. [27] demonstrated on a modern diesel engine that under real driving conditions the effect of TPO on $\mathrm{NO}_{\mathrm{X}}$ emissions is low and far below the inaccuracies resulting from repeatability of the operating conditions.

All the above studies indicated different optimal TPO/DF compositions for CI engine fuelling. Furthermore, inconsistent emission trends were reported in different studies. These discrepancies may result from different TPO properties, stemming from differences in pyrolysis processes and refining. It is sufficient to mention that kinematic viscosity at $40{ }^{\circ} \mathrm{C}$ of tested raw TPO components varied from $2.4 \mathrm{~mm}^{2} / \mathrm{s}$ to $9 \mathrm{~mm}^{2} / \mathrm{s}$.

Murugan et al. [28] proposed subjecting TPO to distillation to reduce the soot content and viscosity of the additive. Distillation enabled the authors to fuel the engine with a mixture containing up to $90 \%$ of distilled TPO. Observed ignition delays were proportional to the content of TPO for all operating conditions. The delayed combustion reduced $\mathrm{NO}_{\mathrm{X}}$ emissions, whereas smoke emissions increased.

Doğan et al. [29] fuelled an engine with refined (pure) TPO. However, combustion of pure TPO caused a deterioration of thermal efficiency. In general, the results showed that higher TPO content gave lower exhaust gas opacity. Changes in $\mathrm{NO}_{\mathrm{X}}$ emissions were moderate, but with pure TPO there was a substantial increase for all tested conditions. Note that these results are opposite to those achieved by Murugan et al. [28]. It should be underlined, however, that properties of the various TPO-derived fuel were different, affecting mixture formation during injection and, subsequently, combustion itself.

Sharma and Murugan [30] investigated the combustion of binary blends of JME and TPO at various compositions. The studies showed that the start of combustion at full engine load for the blends with TPO content of $10 \%$ and $20 \%$ was $1^{\circ}$ of CA earlier than for DF. The study's authors explained that this earlier auto ignition stems from the fact that JME has a higher oxygen content and cetane number than DF. Conversely, a higher TPO content delayed auto-ignition due to the decrease in the cetane number. The authors stated that a $20 \%$ addition of TPO is an optimal fuel composition. In another work, Sharma and Murugan [31] demonstrated improvement in the oxidative stability of Jatropha-originated biofuel by $20 \%$ addition of TPO. Engine tests with this fuel blend showed reduction of smoke emissions when compared to DF.

Koc et al. [32] investigated the effects of biodiesel and TPO additives to DF on a four-cylinder CI engine. Analysis of exhaust emissions from a binary blend (97\% DF and 3\% biodiesel or 3\% TPO) and a tertiary blend (94\% DF, 3\% TPO and 3\% biodiesel) revealed that blends with TPO generated lower $\mathrm{NO}_{\mathrm{X}}$ emissions than binary blends of biodiesel and DF. Moreover, combustion of the ternary fuel blend (TPO, FAME and DF) produced lower CO emissions than the binary blend of TPO and DF. One of the most important conclusions drawn by Koc et al. [32] was that adding TPO to conventional diesel fuel or biofuel could be an effective way to reduce $\mathrm{NO}_{\mathrm{X}}$ emissions. In a follow-up work by Koc and Abdullah [33] the same engine was fuelled with a ternary mixture of TPO, biodiesel and DF $(10 \%, 10 \%$ and $80 \%$, respectively). As well as lowering $\mathrm{NO}_{\mathrm{X}}$ emissions, the addition of TPO was found to reduce the exhaust gas CO concentration. 
The above review of published studies of ternary mixtures in combustion engines shows that testing has been solely with methyl esters of jatropha [30] or rapeseed [21, 28, 34]. There are no available research results for mixtures that include raw bio-oil components. Furthermore, the cited studies were performed mainly on relatively simple singlecylinder engines. Data on the impact of ternary mixtures on the performance of modern multi-cylinder production engines is limited.

This study addresses these knowledge gaps by testing ternary mixtures of directly pressed rapeseed oil, diesel and distilled TPO, mixed at different proportions, in a multi-cylinder, common-rail direct injection engine with factory calibration. An attainable map of steady-state operating points was assessed in the study. The paper discusses the production and physicochemical properties of tested samples and examines emission characteristics, engine operating parameters and engine efficiency.

The full scope of these experiments is further narrowed down to the selected best (in terms of well-to-wheels $\mathrm{CO}_{2}$ footprint and emission trade-off) ternary fuel blend. This is subjected to a detailed in-cylinder measurement-based combustion analysis aimed at providing insight into the prospects of further combustion process optimization. Due to the broad scope of the study, these results are discussed in a separate paper by the authors [35], being Part 2 of the present work.

\section{Materials and methods}

\subsection{Preparation of samples}

\subsubsection{Tire pyrolytic oil}

The industrial sample of TPO was obtained by anaerobic pyrolysis of scrapped, used car tyres (pieces approximately $6 \mathrm{~cm}$ by $6 \mathrm{~cm}$ ), conducted in a discontinuous operation reactor at $450-500{ }^{\circ} \mathrm{C}$ for approximately eight hours. The remaining products of the thermal decomposition of tyres were: pyrolytic gas (used for sustaining the pyrolysis process), carbon black and steel wire (component of tyres). The density at $20^{\circ} \mathrm{C}$, viscosity at $40{ }^{\circ} \mathrm{C}$, acid value, sulphur content, flash point and oxidative stability of supplied TPO samples were determined according to the methodology described in Subsection 2.2. The values of the analyzed physicochemical parameters indicated that pure TPO should not be used directly as a fuel component.

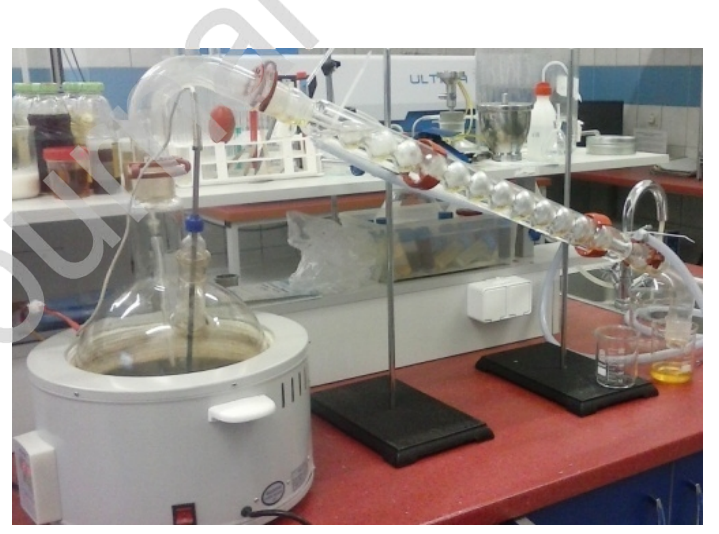

Fig. 1. The laboratory setup used for TPO distillation.

After a basic physicochemical analysis, TPO was distilled in order to remove highly volatile components and soot particles present in the initial sample. Fig. 1 shows the laboratory setup used for TPO distillation, consisting of a heater, a three-neck flask fitted with a mercury thermometer and a thermocouple, a spherical condenser and a collection vessel.

Three fractions differing in terms of boiling temperature were distinguished during distillation:

- Fraction I - consisting of fractions with boiling temperature $>160{ }^{\circ} \mathrm{C}$ - this fraction was distilled in order to remove components characterized by high volatility, significantly influencing the low flash point of the pyrolytic oil;

- Fraction II - consisting of fractions with boiling temperature from $160{ }^{\circ} \mathrm{C}$ to $204{ }^{\circ} \mathrm{C}$ - this fraction was used as a fuel component; 
- Fraction III - consisting of fractions with boiling temperature from $205^{\circ} \mathrm{C}$ to $350{ }^{\circ} \mathrm{C}$ - in the fraction distilled over $204^{\circ} \mathrm{C}$ a soot penetration form pyrolytic oil has occurred; over $350^{\circ} \mathrm{C}$ only tar-like substance remained in the distillation flask.

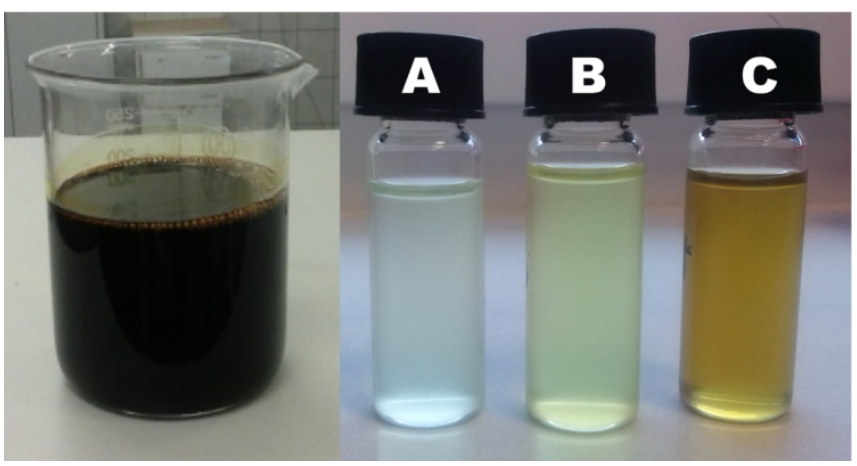

Fig. 2. From the left - obtained raw TPO sample and products of its distillation; A - light naphtha fraction, B - medium naphtha fraction, $\mathrm{C}-$ heavy naphtha fraction.

Fig. 2 presents fractions obtained by distillation. During distillation it was observed that visible soot amounts penetrated into the heavy fraction, which was also noted in the previous works by Ambrosewicz-Walacik and Danielewicz [36], Ambrosewicz-Walacik et al. [35]. Thus, the medium naphtha fraction II, which accounted for 59\% of the total TPO sample mass, was used for further investigations.

\subsubsection{Cold-pressed rapeseed oil}

The Komet screw oil-expeller CA $59 \mathrm{G}$ featuring a cylindrical perforated strainer basket was used to extract rapeseed oil at a temperature below $40{ }^{\circ} \mathrm{C}$. The seeds were thermally treated at $130{ }^{\circ} \mathrm{C}$ for an hour and then cooled down before extraction. Mechanical impurities were filtered by centrifugation at $12000 \mathrm{rpm}$ for 10 minutes in a centrifuge type C 5810 R (Eppendorf, Germany).

\subsubsection{Rapeseed methyl esters}

The sample of crude pressed RO was subjected to transesterification to obtain RME which were used as fuel components. In the first step of RME preparation, the acid number of crude RO was determined to select the right method for transesterification. Due to a low value of this parameter $(2.0 \mathrm{mg} \mathrm{KOH} / \mathrm{g})$, a single-base transesterification method was chosen. The reaction was carried out in $500 \mathrm{ml}$ glass flasks placed in electric heaters. Weighed portions of $300 \mathrm{~g}$ of oil were heated to $60 \pm 1^{\circ} \mathrm{C}$. Next, a solution of potassium methoxide $(3.75 \mathrm{~g} \mathrm{KOH}$ mixed with $125 \mathrm{ml}$ of methanol) was added to the preheated oil. The reaction was carried out at $60 \pm 1^{\circ} \mathrm{C}$ for 1 hour with stirring at a rate of $250 \mathrm{rpm}$. The reacted mixture was then distilled in a vacuum evaporator from Heidolph (Germany) to remove any residue. Afterwards, the mixture was subjected to separation for 24 hours. When the sedimentation phases were separated, an approximate yield of the process based on the percentage of ester $(94.2 \%)$ and glycerine phases $(5.8 \%)$ was determined.

\subsubsection{Diesel fuel}

The sample of diesel fuel was supplied from a commercial fuel station in Olsztyn, Poland. The fuel's specification complied with EN590 standard and it already contained a 7\% biocomponent.

\subsection{Properties of fuels}

The crude TPO, distilled TPO fractions of naphtha, RME, crude rapeseed oil and diesel fuel were analyzed to determine viscosity at $40{ }^{\circ} \mathrm{C}$ (pycnometric method), density at $15{ }^{\circ} \mathrm{C}$ (EN ISO 3104), acid number (EN 14104), sulphur content (ISO 20884), flash point (ISO 3679), cold filter plug point (EN 116), oxidative stability (EN 14112) and calorific value (D4809). The properties of the tested fuels and their components are listed in Table 1. The distillated medium fraction naphtha of TPO $\left(\mathrm{DMF}_{\mathrm{TPO}}\right)$ was selected for the composition of ternary fuel blends. Interestingly, $\mathrm{DMF}_{\mathrm{TPO}}$ has a very low viscosity, so can be used as a viscosity enhancer for biocomponents. Also note that the flash 
point of $\mathrm{DMF}_{\mathrm{TPO}}$ is very low, which eventually will have a significant effect on both flammability and handling safety of fuel mixtures with TPO additives.

Table 1. Properties of fuel components used in this study.

\begin{tabular}{|c|c|c|c|c|c|c|}
\hline \multirow{2}{*}{ Samples } & \multirow{2}{*}{ ТРО } & \multicolumn{3}{|c|}{ Distilled fraction of naphtha from TPO } & \multirow{2}{*}{ RO } & \multirow{2}{*}{$\mathrm{DF}$} \\
\hline & & light & medium & heavy & & \\
\hline viscosity at $40{ }^{\circ} \mathrm{C}\left[\mathrm{mm}^{2} / \mathrm{s}\right]$ & 5.59 & 0.814 & 0.842 & 0.897 & 39 & 2.73 \\
\hline density at $15^{\circ} \mathrm{C}\left[\mathrm{kg} / \mathrm{m}^{3}\right]$ & 949 & 779 & 1008 & 1361 & 920 & 827 \\
\hline $\begin{array}{c}\text { acid value } \\
{[\mathrm{mg} \mathrm{KOH} / \mathrm{g}]}\end{array}$ & 4.63 & 2.37 & 3.12 & 3.88 & 2.00 & 0.07 \\
\hline sulphur content [wt $\%]$ & 0.42 & 0.34 & 0.54 & 0.79 & 0.007 & 0.006 \\
\hline $\begin{array}{c}\text { flash point } \\
{\left[{ }^{\circ} \mathrm{C}\right]}\end{array}$ & 53 & $<3.5$ & 13 & 23 & $>200$ & 57 \\
\hline cold filter plug point $\left[{ }^{\circ} \mathrm{C}\right]$ & n.d. & $>-30$ & $>-30$ & $>-30$ & n.d. & -1 \\
\hline oxidative stability $[\mathrm{h}]$ & $>27$ & 0.5 & $>27$ & $>27$ & 6.47 & $>22$ \\
\hline
\end{tabular}

Prior to engine tests, different ternary fuel blends consisting of DF, RO and $\mathrm{DMF}_{\mathrm{TPO}}$ were prepared and tested for their flash point to verify the safety of fuel application. This indicated that to ensure a safe flash point (above $55^{\circ} \mathrm{C}$ according to $\mathrm{EN} 590$ ), the $\mathrm{DMF}_{\mathrm{TPO}}$ content cannot exceed $5 \%$. Thus, ternary fuel blends were composed of different fractions of $\mathrm{DF}$ and $\mathrm{RO}$ with a constant $\mathrm{DMF}_{\mathrm{TPO}}$ content of $5 \%$ on a mass basis. The ternary fuel blends subjected to further examinations were denoted as $\mathrm{TPO}_{1}$ up to $\mathrm{TPO}_{5}$, and composed according to Table 2 .

To provide a baseline for the assessment of effects of the $\mathrm{DMF}_{\mathrm{TPO}}$ addition, a binary blend of DF and RO (denoted as DR) with equal shares of both components was examined as well. This fuel was not, however, subjected to engine tests. It was noted that the addition of $\mathrm{DMF}_{\mathrm{TPO}}$ positively influenced the viscosity, density and acid number of the ternary blends when compared with the DR sample. Nevertheless, despite a significant decrease in viscosity, the value of prepared ternary fuel blends exceeded the acceptable limit of $4.5 \mathrm{~mm}^{2} / \mathrm{s}$, specified in EN 590 . The viscosity ranged from $6.63 \mathrm{~mm}^{2} / \mathrm{s}$ to $11.56 \mathrm{~mm}^{2} / \mathrm{s}$, as shown in Table 2. Furthermore, the content of sulphur in selected blends significantly exceeded the permissible content of that compound (10 mg/kg according to EN 590), and for that reason it is suggested to desulfurize the crude TPO before distillation.

Further engine tests were conducted using five selected ternary blends. To provide reference values, pure DF and a blend of rapeseed methyl ester and DF $\left(20: 80\right.$, v/v), denoted as $\mathrm{Bio}_{20}-\mathrm{DF}_{80}$, were used. Properties of all tested fuels are given in Table 2 .

Table 2. The composition of individual fuel blends prepared for pilot analysis, along with most relevant physicochemical properties.

\begin{tabular}{|c|c|c|c|c|c|c|c|c|}
\hline Samples & DR & DF & $\mathrm{TPO}_{1}$ & $\mathrm{TPO}_{2}$ & $\mathrm{TPO}_{3}$ & $\mathrm{TPO}_{4}$ & $\mathrm{TPO}_{5}$ & $\begin{array}{l}\mathrm{Bio}_{20^{-}} \\
\mathrm{DF}_{80}\end{array}$ \\
\hline $\begin{array}{l}\text { composition } \\
\text { DF/RO/DMF * } \\
{[\% \text { volume }]}\end{array}$ & $50 / 50 /-$ & $100 /-/-$ & $40 / 55 / 5$ & $45 / 50 / 5$ & $50 / 45 / 5$ & $55 / 40 / 5$ & $65 / 30 / 5$ & $80 / 20 /-$ \\
\hline flash point $\left[{ }^{\circ} \mathrm{C}\right]$ & $>100$ & 57.0 & 54.5 & 55.0 & 56.0 & 56.5 & 57.0 & 57.0 \\
\hline $\begin{array}{l}\text { viscosity at } 40 \\
{ }^{\circ} \mathrm{C}\left[\mathrm{mm}^{2} / \mathrm{s}\right]\end{array}$ & 17.82 & 2.73 & 11.56 & 8.94 & 8.43 & 7.97 & 6.63 & 2.99 \\
\hline $\begin{array}{l}\text { density at } 15 \\
{ }^{\circ} \mathrm{C}\left[\mathrm{kg} / \mathrm{m}^{3}\right]\end{array}$ & 875 & 827 & 868 & 861 & 860 & 852 & 851 & 834 \\
\hline $\begin{array}{l}\text { acid value } \\
{[\mathrm{mg} \mathrm{KOH} / \mathrm{g}]}\end{array}$ & 0.81 & 0.07 & 0.68 & 0.73 & 0.63 & 0.62 & 0.63 & 0.20 \\
\hline $\begin{array}{l}\text { sulphur content } \\
{[\mathrm{mg} / \mathrm{kg}]}\end{array}$ & 6.12 & $<0.1$ & 271.6 & 277.5 & 274.5 & 276.1 & 140.3 & 4.8 \\
\hline $\begin{array}{l}\text { oxidative } \\
\text { stability }[\mathrm{h}]\end{array}$ & 9.25 & $>22$ & $>5.86$ & $>5.86$ & 6.02 & 8.84 & 6.63 & $>20$ \\
\hline $\begin{array}{l}\text { Lower heating } \\
\text { value }[\mathrm{MJ} / \mathrm{kg}]\end{array}$ & n.d. & 44.5 & 39.5 & 39.6 & 40.1 & 40.7 & 41.1 & 43.8 \\
\hline
\end{tabular}

\subsection{Engine test setup and methodology}

The fuel samples were tested on an engine test bench with a four-cylinder, medium-duty compression-ignition engine manufactured by Andoria-Mot Poland. The engine was equipped with a Bosch common-rail 2.0 fuel injection 
system and controlled by a factory EDC1639 engine control unit. Technical specifications of the test engine are listed in Table 3 and its layout is illustrated in Fig. 3.

The engine was installed on a test bench and equipped with the following measurement equipment:

- eddy-current dynometer (AVL DP 240),

- fuel balance AVL 735S with temperature conditioning,

- air mass flow meter SENSYFLOW P from ABB,

- in-cylinder pressure measurement system (KISTLER),

- test stand control and data acquisition system (AVL PUMA Open),

- partial flow dilution emission measurement system (AVL AMA I60),

- smoke meter (AVL 552).

Additionally, a set of absolute pressure and temperature transducers was installed at various locations of the air and exhaust paths to monitor and control the media (cooling water, lube oil). A schematic diagram of the engine environment with the most important measurement points is shown in Fig. 3. Measurement accuracies of the instruments are given in Table 4.

Table 3. Technical data of the test engine.

\begin{tabular}{|c|c|}
\hline Type & 4-stroke, Compression-Ignition \\
\hline Engine layout & 4 cylinder inline, vertical \\
\hline Cylinder diameter / piston travel & $94 / 95 \mathrm{~mm}$ \\
\hline Displacement volume & $2636 \mathrm{~cm}^{3}$ \\
\hline Compression ratio & $17.5: 1$ \\
\hline Rated Power / rotational speed & $85 \mathrm{~kW} / 3,700 \mathrm{rpm}$ \\
\hline Max. Torque / rotational speed & $250 \mathrm{Nm} / 1,800-2,200 \mathrm{rpm}$ \\
\hline Injection system & Bosch injection system CR 2.0 \\
\hline Turbocharger & radial, with exhaust extraction valve \\
\hline EGR & High pressure system, pneumatic valve \\
\hline
\end{tabular}

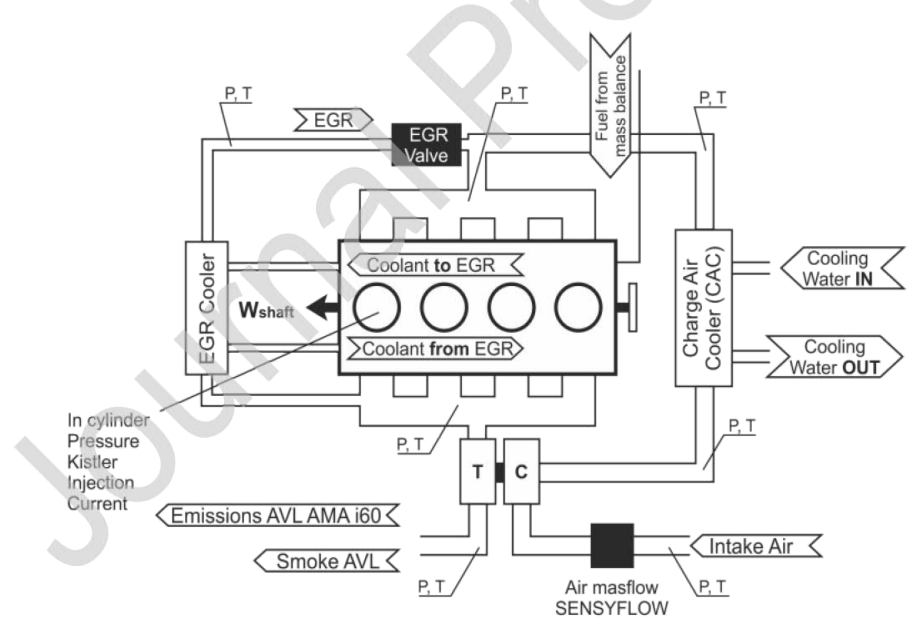

Fig. 3. Test engine layout with most important measurement points. Note that EGR valve was turned off in the present research.

The scope of the present paper includes analysis of emission, efficiency and selected performance parameters. Therefore, for the present analysis, only the relevant measurement systems will be discussed in detail. For further information on the engine test bench, the reader is referred to earlier works by the authors [37, 38]. For a detailed description of in-cylinder pressure measurements and thermodynamic analysis, refer to the second part of this work devoted to combustion analysis [17]. Here it is only relevant to mention that the in-cylinder pressure, along with the injection actuation current, were recorded with a CA resolution of $0.1^{\circ}$. The presented pressure and HRR curves are ensemble-averaged for 200 consecutive engine cycles.

Fuel consumption was measured using the AVL 735S fuel balance. The fueling system was equipped with an accurate thermal management unit that controlled fuel temperature on the intake and return lines via heat exchangers. The tested fuels were changed by switching the fuel tanks. Exceptional care was taken to ensure results reliability with such radically different fuels, purging the fuel system before each test sequence using a set of valves. The engine was then allowed to run on a new fuel with the injector pump return hose disconnected. Purging continued until a sufficient 
amount of fuel was transferred through the engine fueling system as well as the measurement and conditioning devices.

The emission test bench consisted of the following analyzers:

- Flame Ionization Detector (FID) - for measurements of THC concentrations,

- Chemiluminescence Detector (CLD) - for measurements of $\mathrm{NO}_{\mathrm{X}}$ concentrations,

- 2 x Infrared Detector (IRD) - calibrated for CO concentration,

- Paramagnetic Detector (PMD) - for $\mathrm{O}_{2}$ concentration measurement.

All the sample lines leading to the exhaust analyzers where heated to $150{ }^{\circ} \mathrm{C}$ to avoid water condensation that might affect results. Additionally, EGO was measured using the AVL smoke meter (AVL 552).

The emission paths were carefully flushed with a high flux of pressurized air between different fuels, adhering to a procedure provided by the emission test bench manufacturer (AVL).

Table 4. List of the most relevant (low-frequency) parameters recorded directly, along with achieved maximum uncertainty.

\begin{tabular}{|c|c|c|c|c|c|c|c|c|c|}
\hline Parameter & 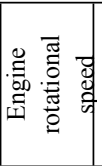 & 总 & 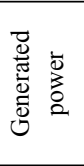 & 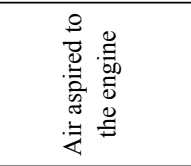 & 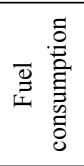 & 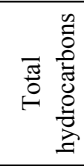 & 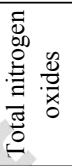 & 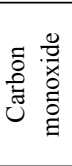 & 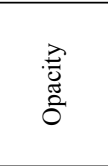 \\
\hline Symbol & $\mathrm{N}$ & $\mathrm{Te}$ & $\mathrm{Pe}$ & $\mathrm{G}_{\text {air }}$ & $\mathrm{G}_{\text {fuel }}$ & THC & $\mathrm{NO}_{\mathrm{x}}$ & $\mathrm{CO}$ & EGO \\
\hline Measurement device & \multicolumn{3}{|c|}{ AVL DP 240} & SENSYFLOW P & $\begin{array}{l}\text { AVL } \\
735 \mathrm{~S}\end{array}$ & \multicolumn{3}{|c|}{ AVL AMA i60 } & AVL 439 \\
\hline Uncertainty level & \pm 5 & \pm 2 & \pm 0.2 & \pm 0.5 & \pm 0.1 & \pm 11 & \pm 19 & \pm 13 & \pm 0.9 \\
\hline Unit & RPM & $\mathrm{Nm}$ & $\mathrm{kW}$ & $\mathrm{kg} / \mathrm{h}$ & $\mathrm{kg} / \mathrm{h}$ & ppm & ppm & ppm & $\%$ \\
\hline
\end{tabular}

The research assessed the steady-state operation of the engine. For each of the operating points, after stabilization of the engine operating conditions (120 s), a measurement window was set to $180 \mathrm{~s}$, during which the parameters listed in Table 4 were recorded. The sampling rate for the parameters was maintained constant $(1 \mathrm{~s})$, and time-averaged values are further analyzed in the Results section.

\subsection{Calculation methodology}

In the present study, the directly measured concentrations of toxic exhaust gas components and opacity were used to characterize the investigated fuels. Since the goal is to compare the environmental impact of different fuels at the same engine operating conditions, such an approach is more informative since it allows assessment of the emission output without introducing the bias resulting from engine efficiency. Thus, presented emission results are time-averaged direct outputs of the respective analyzers. Either the standard deviation calculated for a time series or the device accuracy (Table 4), whichever is higher, are taken as the maximum uncertainty of individual emission indexes.

Fuel efficiency analysis relies on the values of BTE, calculated as a ratio of power generated by the engine and energy input introduced with a specific fuel. Namely, using the directly measured quantities introduced in Table 4:

$$
B T E[\%]=100 \cdot \frac{P e \cdot 3600}{G_{\text {fuel }} \cdot L H V_{\text {fuel }}}
$$

Note that LHVs differ for the tested fuels due to differences in chemical composition. Thus, they were determined for each fuel, and are summarized in Table 2. The uncertainty level for the BTE was established from the maximum device accuracies of the directly measured inputs (Table 4) using the exact differential method, following the approach of Klien and McClintock [39].

The present work provides also some details concerning in-cylinder pressure analysis. The net IMEP was calculated by integrating the pressure signal across the whole $720 \mathrm{CA}$ respectively. The coefficient of variation in IMEP $\left(\mathrm{COV}_{\mathrm{IMEP}}\right)$ was introduced as an indicator for operational stability. This parameter was calculated for 200 subsequent engine cycles as a ratio of standard deviation and mean value. The average peak pressures and their standard deviations were used as measures for cycle-to-cycle variations.

The net IMEP was further used to calculate indicated efficiency

$$
\eta_{\text {net }}=100 \cdot \frac{1 / 2 \cdot \mathrm{IMEP}_{\text {net }} \cdot V_{\text {disp }} \cdot N \cdot 3600}{G_{\text {fuel }} \cdot L H V_{\text {fuel }}}
$$

where $V_{\text {disp }}$ is the displaced volume and $N$ denotes the engine rotational speed. Note that the differences between net indicated efficiency and BTE are the total friction losses. Combustion losses were calculated on the basis of recorded 
THC and CO concentrations. This was done on a simplifying assumption that all unburned HCs account for n-heptane particles yet have the heating value of the corresponding fuel. Then, the combustion losses become:

$$
\eta_{\text {comb }}=\frac{G_{C O} L H V_{C O}+G_{T H C} L H V_{\text {fuel }}}{G_{\text {fuel }} \cdot L H V_{\text {fuel }}}
$$

where $\mathrm{G}$ terms with the subscripts $\mathrm{CO}$ and THC represent the concentrations of the corresponding species recalculated with the total exhaust flow rate to the adopted convention of mass flow as in Eq.1 and Eq. 2.

The injection current was recorded using the same sampling frequency as in-cylinder pressure. The first-order derivative of this signal was used to determine the SOA angle by means of a simple peak sensing routine. Thus, the maximum accuracy of this parameter was considered to be equal to twice the sampling rate (0.2 CA). For more information on the methodology of in-cylinder pressure analysis adopted in this research, the reader is referred to other works by Mikulski et. al. [37, 40, 41].

\subsection{Scope of the research}

Steady-state measurements were performed at two engine speeds: $1500 \mathrm{rpm}$ and $3000 \mathrm{rpm}$. For both engine speeds, an engine-load sweep was performed by changing the Te value from $50 \mathrm{Nm}$ to $200 \mathrm{Nm}$ with a step size of 25 . This covered the operational map up to $80 \%$ nominal engine load. The corresponding BMEP values ranged from 2.4 bar to 9.5 bar for all operating points. Note that $100 \%$ rated diesel load point was not investigated in this study due to the inability of reaching this point for $\mathrm{TPO}_{1}$ and $\mathrm{TPO}_{2}$ samples. This was associated with limitations of the current injection aperture.

The research was performed without external EGR, using factory injection and turbocharger maps. This was done to assess the study's thesis that the combustion properties of raw vegetable oil - diesel mixtures can be significantly and positively altered by adding distilled pyrolytic oils.

\section{Results and discussion}

The objective of the work is to provide the complete characterization of different ternary fuel mixtures containing distilled TPO in terms of combustion performance and emissions for a wide range of engine operating points, and to asses them with respect to $\mathrm{DF}$ and $\mathrm{Bio}_{20}-\mathrm{DF}_{80}$ references. Given the broad scope of the research, the details of combustion characteristics are not elaborated. It is however considered necessary for the reader to gain some understanding of the combustion strategy in general, so results of a detailed combustion analysis (in-cylinder pressure and HRR) for selected operating points are discussed in Subsection 3.1. A full factorial characterization is further performed based on selected efficiency (Subsection 3.2) and emission (Subsection 3.3) indicators. For a detailed combustion analysis accounting for the observed differences, the reader is referred to another work by the authors [17].

\subsection{The combustion strategy}

Figs. 5 and 6 show the results of processed injection current, in-cylinder pressure and heat release rate for two selected operating points from the experimental matrix. Namely, the figures refer to the same mid-load point of 6 bar BMEP $(125 \mathrm{Nm})$ at the engine speed of $1500 \mathrm{rpm}$ and $3000 \mathrm{rpm}$ respectively. 

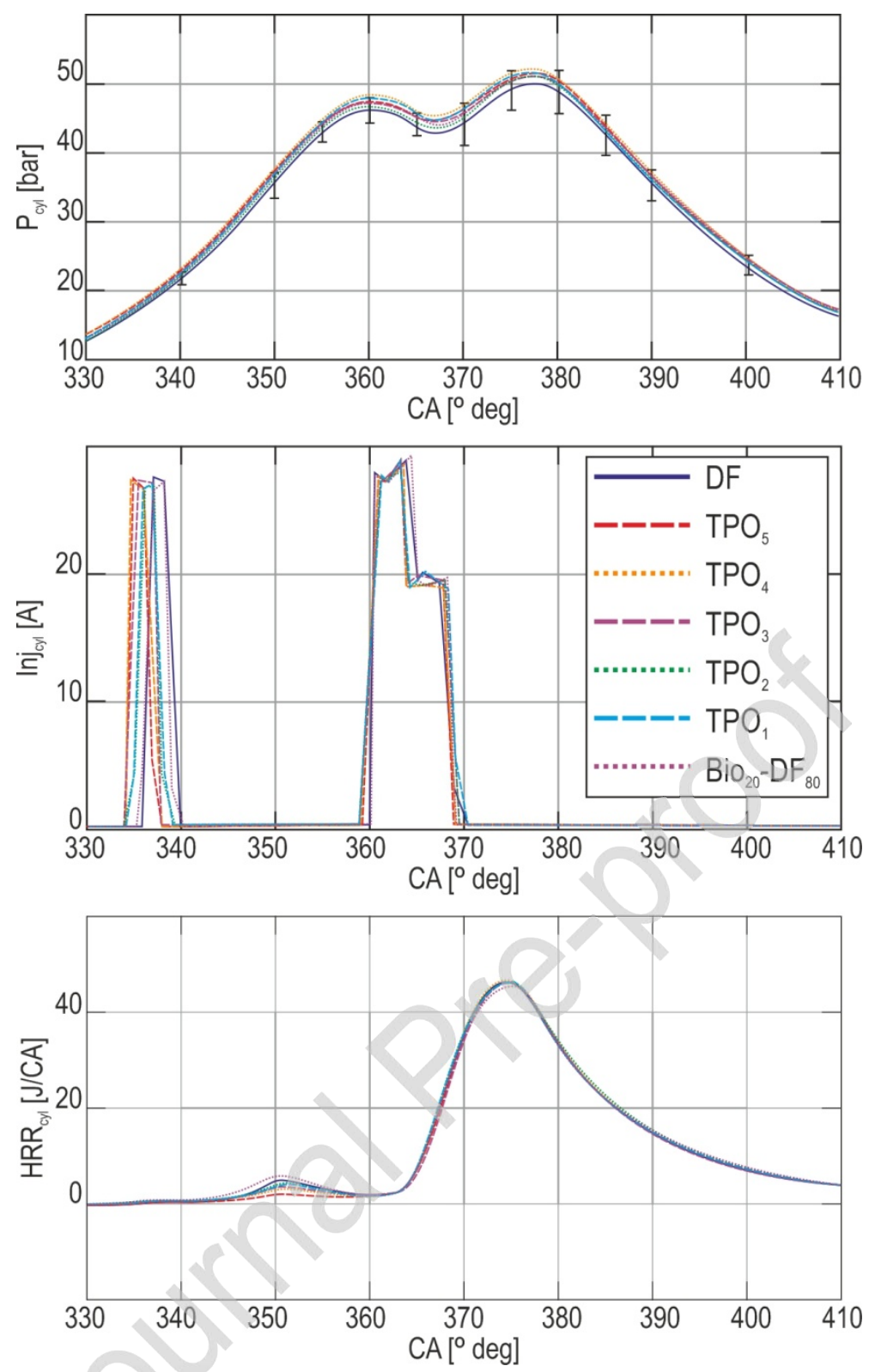

Fig. 5. Cycle-averaged injection current, in-cylinder pressure and HRR; $N=1500 \mathrm{rpm}, \mathrm{Tq}=125 \mathrm{Nm}$. Error bars for in-cylinder pressure denote cycle-to-cycle variations (for clarity plotted only for DF results). 

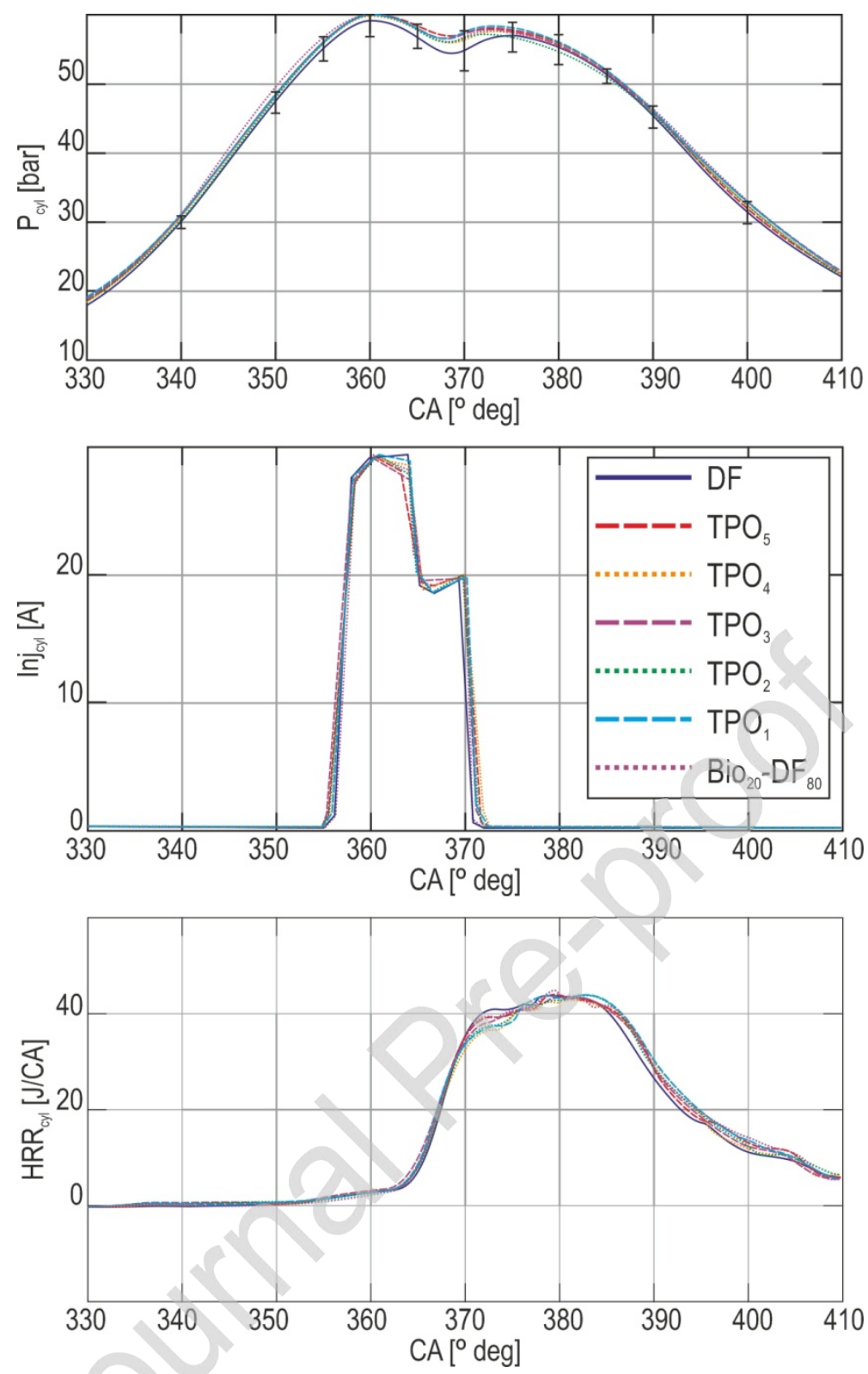

Fig. 6. Cycle-averaged injection current, in-cylinder pressure and HRR; $N=3000 \mathrm{rpm}, \mathrm{Tq}=125 \mathrm{Nm}$. Error bars for in-cylinder pressure denote cycle-to-cycle variations (for clarity plotted only for DF results).

Comparing Fig. 5 and Fig. 6 one can immediately note that the engine realizes a different injection strategy for both operating points. This observation can be applied across the whole test matrix. Namely, split injection is realized for all cases with the engine speed of $1500 \mathrm{rpm}$, while at $3000 \mathrm{rpm}$ the engine employs a single injection mode. The multipulse strategy with early injection of a relatively small pilot amount of fuel (around $10 \%$ of the overall fuel quantity independently of engine load) exhibits a clear premixed combustion phase, which can be seen in the HRR plot in Fig. 5. For the single injection, combustion is clearly diffusion-controlled by a developing spray which can be recognized by a distinctive flat HRR profile in Fig. 6. Note that in both analyzed cases the main combustion phase is significantly retarded, beyond the TDC. This strategy is often used as a $\mathrm{NO}_{\mathrm{x}}$ emission-mitigation measure. It reduces peak incylinder temperatures while sacrificing indicated efficiency $[42,43]$. Comparing the HRRs of individual fuels, one can note that combustion is not significantly affected by fuel choice. The in-cylinder pressure traces are also similar (within cycle-to-cycle variations) for both analyzed operating points. Note however that for the case presented in Fig. 5, the engine controller is able to maintain the preset combustion parameters adjusting on the pilot injection timing. The extent 


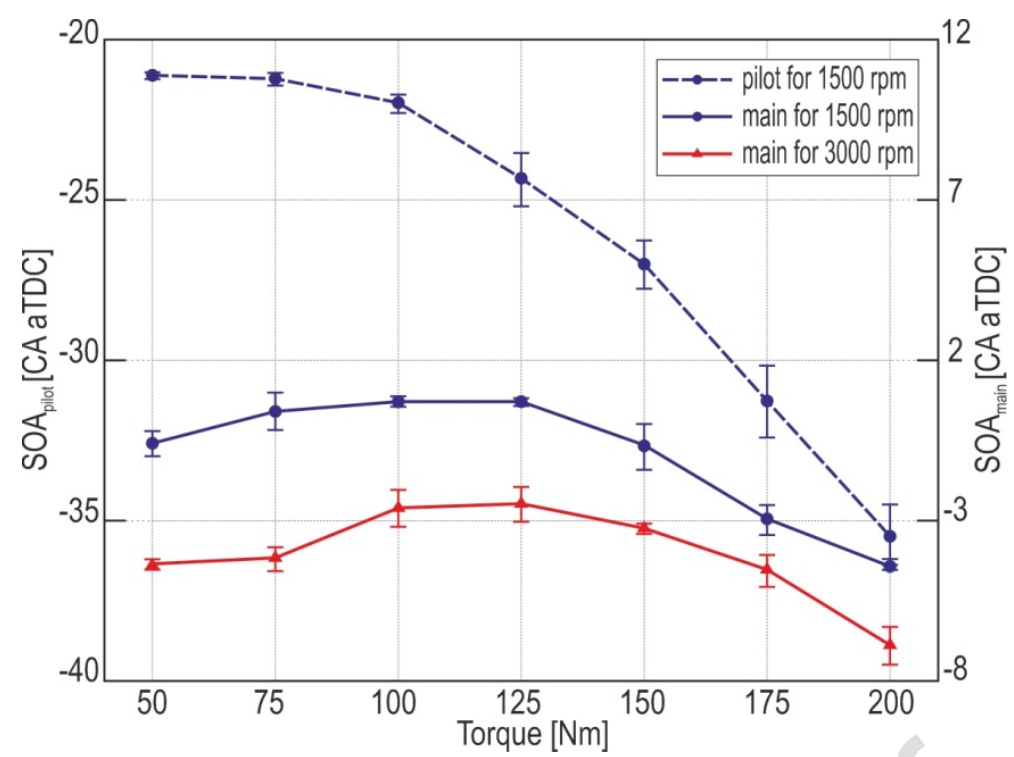

Fig. 7. Start of actuation of pilot injection and main injection for diesel fuel and all investigated conditions. Error bars denote maximum dispersion between different fuels. Note separate Y-axes for pilot and main injections.

While analyzing the trends in SOA, one should keep in mind that the absolute, maximum error of determining the timing was 0.2 CA. Cycle-to-cycle variations in SOA were not recorded in the present research.

From Fig. 7 one can observe that the pilot injection (when applied) is generally retarded with increasing engine load, from around $21 \mathrm{CA}$ bTDC at the lowest load up to $36 \mathrm{CA}$ bTDC for the $200 \mathrm{Nm}$ case. For the main injections, the trends were non-monotonic in terms of both engine loads. Note however that the largest variations from fuel to fuel were rather small and did not exceed 1.5 CA deg. With the small yet noticeable variations in engine operating parameters, the extent to which the overall engine performance is affected by fuel can differ, depending on the operating point. This is assessed in subsequent subsections with respect to combustion stability, thermal efficiency and emissions.

\subsection{Combustion stability and cycle-to-cycle variations}

The $\mathrm{COV}_{\text {IMEP }}$ is a widely used indicator for assessing combustion stability. More accurately, it determines the engine's capability for providing stable torque output, which is important in terms of drivability for vehicle applications and efficiency [44]. More importantly, for power generation, torque instability will introduce frequency or current output oscillations. A typically assumed stability limit for different applications is $\operatorname{COV}_{\text {IMEP }}$ that does not exceed $5 \%$ $[45,46]$.

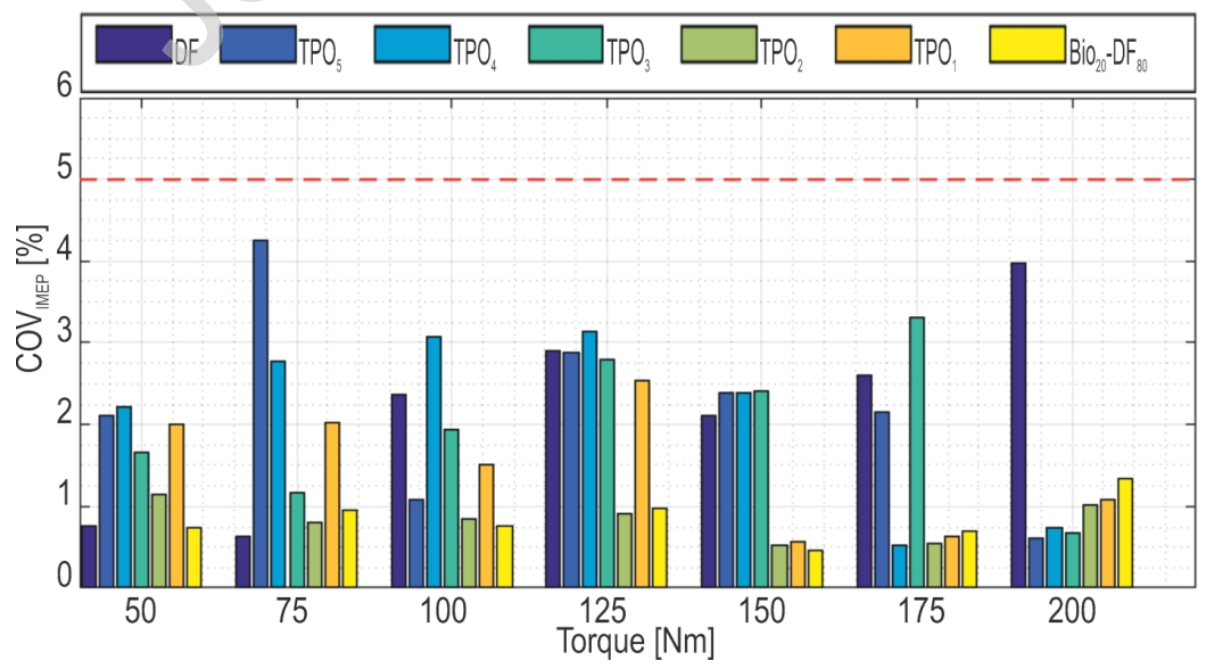

430 Fig. 8. Coefficient of variation in IMEP for different fuels across the whole engine load sweep; $\mathrm{N}=1500 \mathrm{rpm}$. 


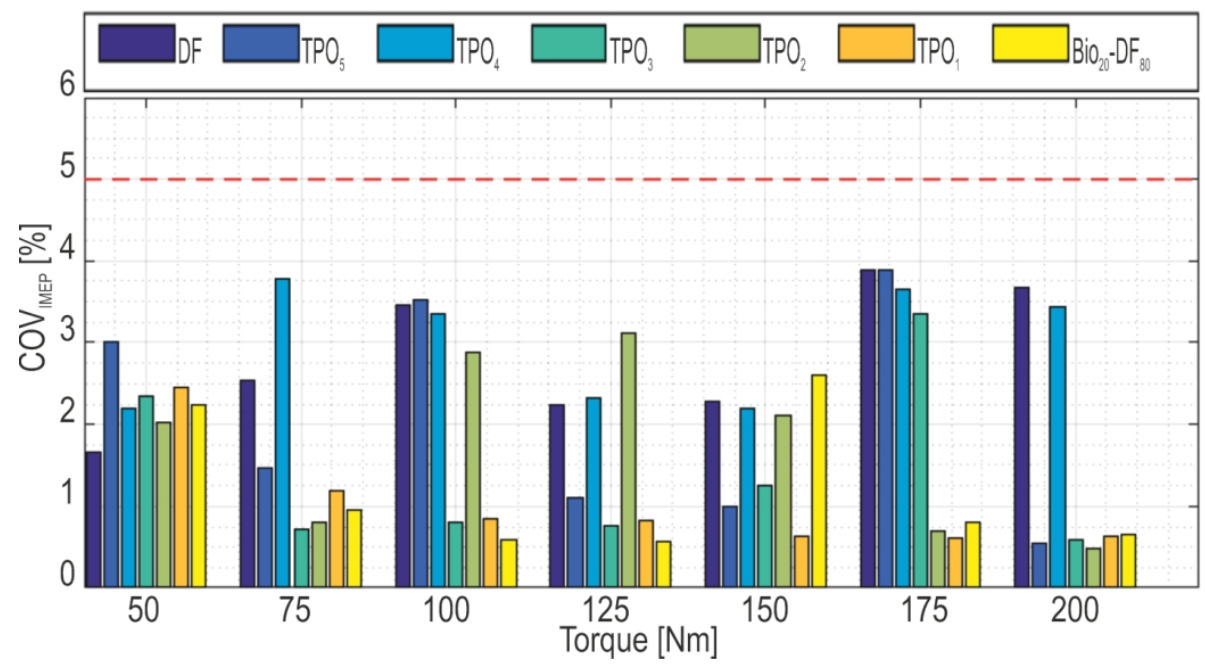

Fig. 9. Coefficient of variation in IMEP for different fuels across the whole engine load sweep; $\mathrm{N}=3000 \mathrm{rpm}$.

Figs. 8 and 9 show how this parameter is influenced by a given fuel for the engine speeds of $1500 \mathrm{rpm}$ and 3000 rpm, respectively. It can be seen that all fuel samples were able to meet the adopted stability criterion at all operating points, although at selected operating points the combustion variability was rather high and exceeded $3 \% \mathrm{COV}_{\text {IMEP }}$. Note however that this variability apparently can be attributed to the engine itself rather than the type of fuel used, since in the standard DF operation the $\mathrm{COV}_{\text {IMEP }}$ is equal or higher compared to other fuel samples. In effect, the stability results are rather stochastic in nature, even though the $\mathrm{Bio}_{20}-\mathrm{DF}_{80}$ showed more stable operation compared with diesel and all TPO mixtures. Consequently, the TPO samples with the lowest admixture of pure rapeseed oil have the physicochemical properties resembling those of diesel fuel, which resulted in the highest levels of variations.

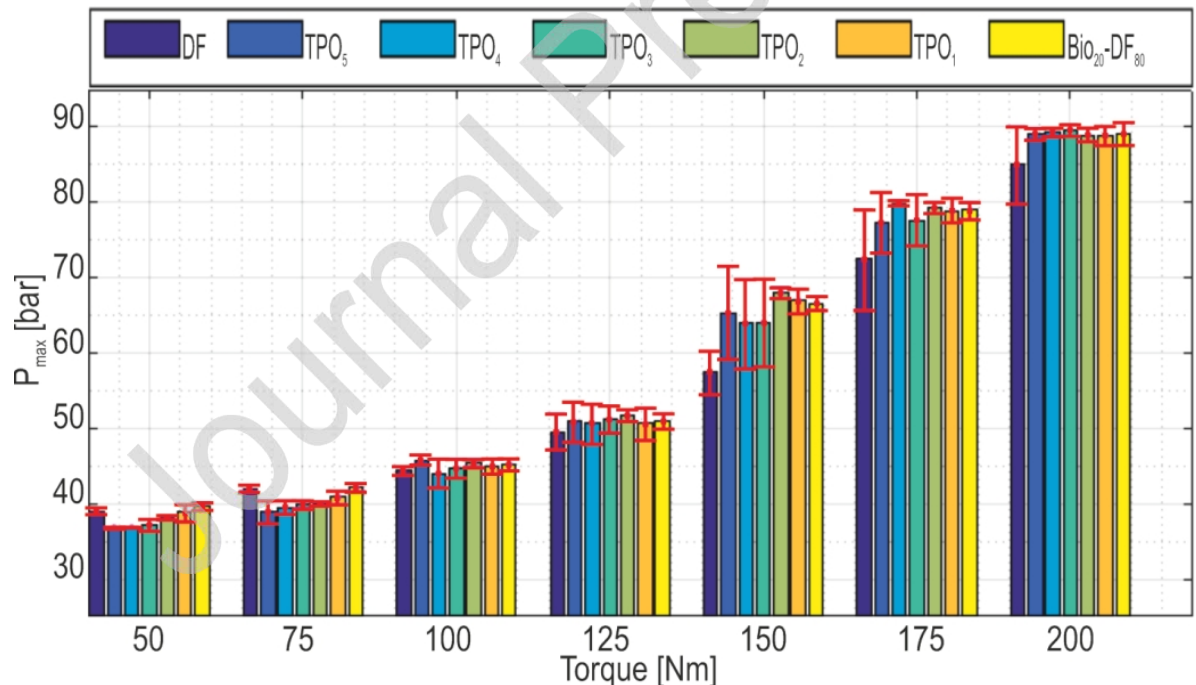

Fig. 10. Peak in-cylinder pressure for different fuels across the whole engine load sweep; $N=1500 \mathrm{rpm}$. Error bars denote standard deviation of $\mathrm{P}_{\max }$ calculated over 200 cycles. 


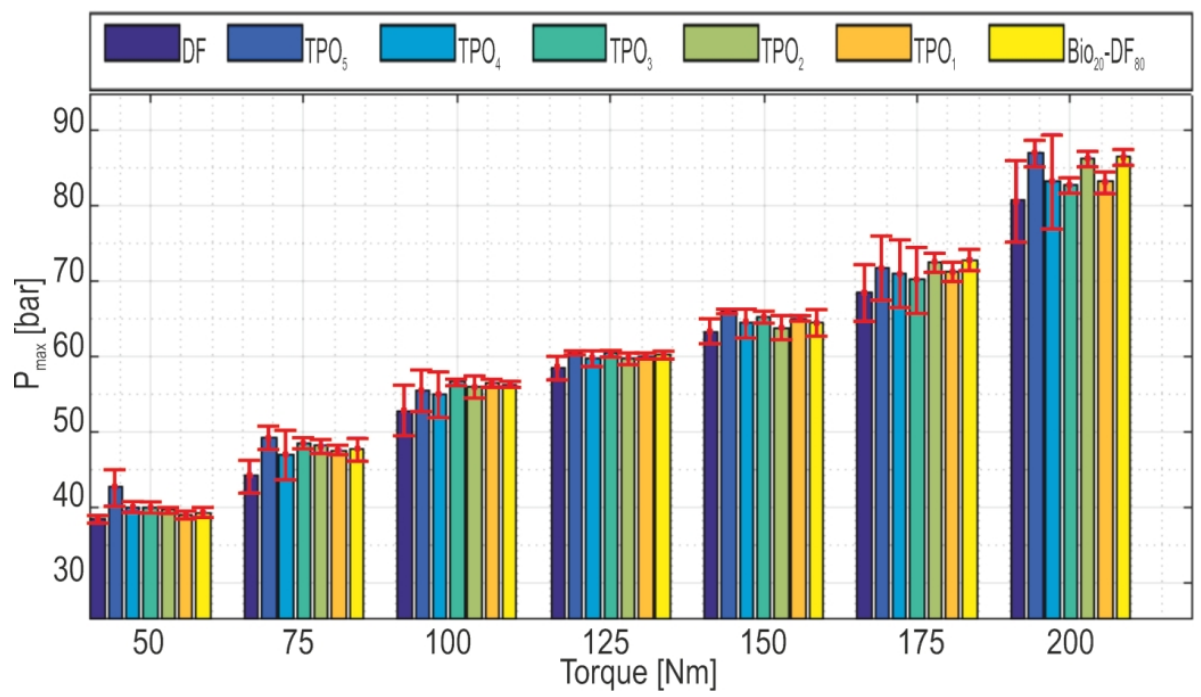

Fig. 11. Peak in-cylinder pressure for different fuels across the whole engine load sweep; $N=3000 \mathrm{rpm}$. Error bars denote standard deviation of $\mathrm{P}_{\max }$ calculated over 200 cycles.

Figs. 10 and 11 show how the cycle-to-cycle oscillations translate into variability of peak in-cylinder pressure. The maximum peak pressure is one of the engine design constraints. Excessive pressures may exert mechanical and thermal stress on combustion chamber components, leading to engine failure. The peak in-cylinder pressures generally increase with engine load, which is obvious since more energy is released during combustion. One can note that all biofuels show generally similar peak pressures that are usually slightly higher than the reference diesel fuel's. The differences, however, always lie within the cycle-to-cycle variations showed by the error bars. Importantly, comparing Figs. 10 and 11 with Figs. 8 and 9 one can note that the peak pressure variations only partially correspond to the variations in IMEP. For instance, the $50 \mathrm{Nm}$ case with $1500 \mathrm{rpm}$ shows a similar COV IMFP for TPO samples 5, 4 and 2, while for the latter sample the variations in $\mathrm{P}_{\max }$ are substantially higher. Despite that, the peak pressure limit (130 bar for the given engine) was not exceeded for the tested fuels either in terms of cycle-averaged values or in individual cycles. The results presented in this subsection confirm that all tested biofuels can be operated on the engine without exceeding the stability tolerances.

\subsection{Efficiency breakdown analysis}

Figures 14 and 15 present the results of B'TE for the engine operated on different fuels. It is important to know that the maximum error of determining the BTE on the basis of measured fuel consumption and power output was below $0.6 \%$, with its values consistently decreasing with increasing engine load. For example, for the highest power output (200 Nm / $3000 \mathrm{rpm}$ ) the absolute error did not exceed $0.06 \%$. Due to this very small measurement uncertainty, errorbars are omitted in Figs. 12 and 13, but accuracy of BTE estimation is clearly indicated in the discussion of the results.

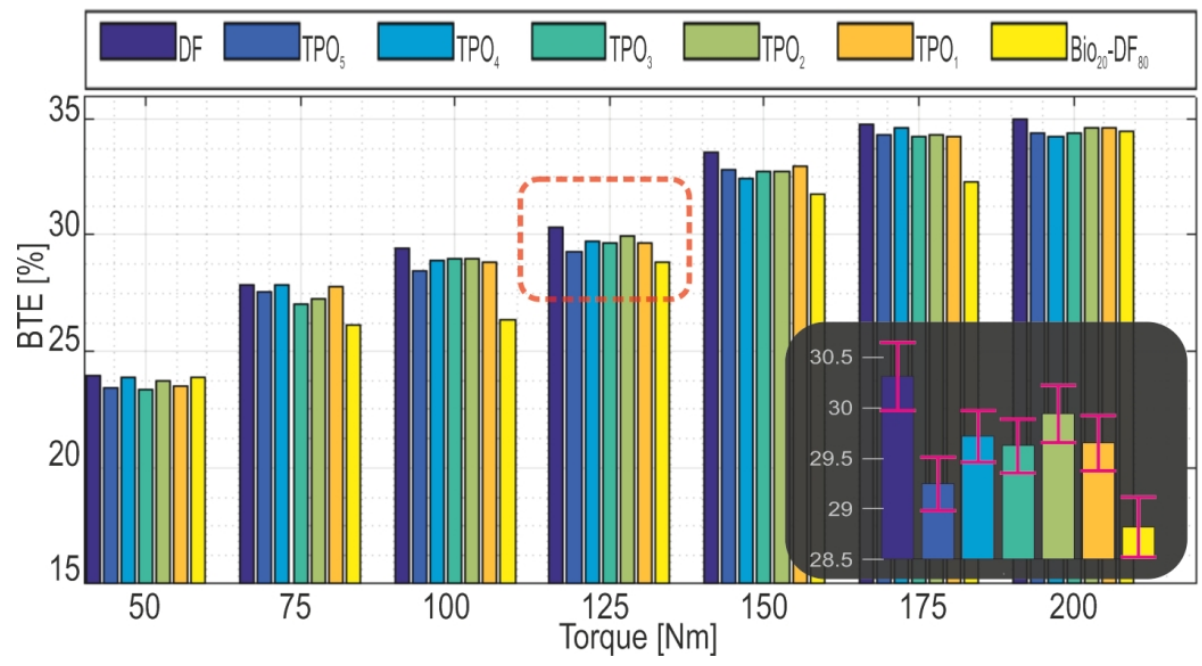


Fig. 12. Brake thermal efficiency; $N=1500 \mathrm{rpm}$. Error bars (for a chosen operating point) denote the maximum uncertainty.

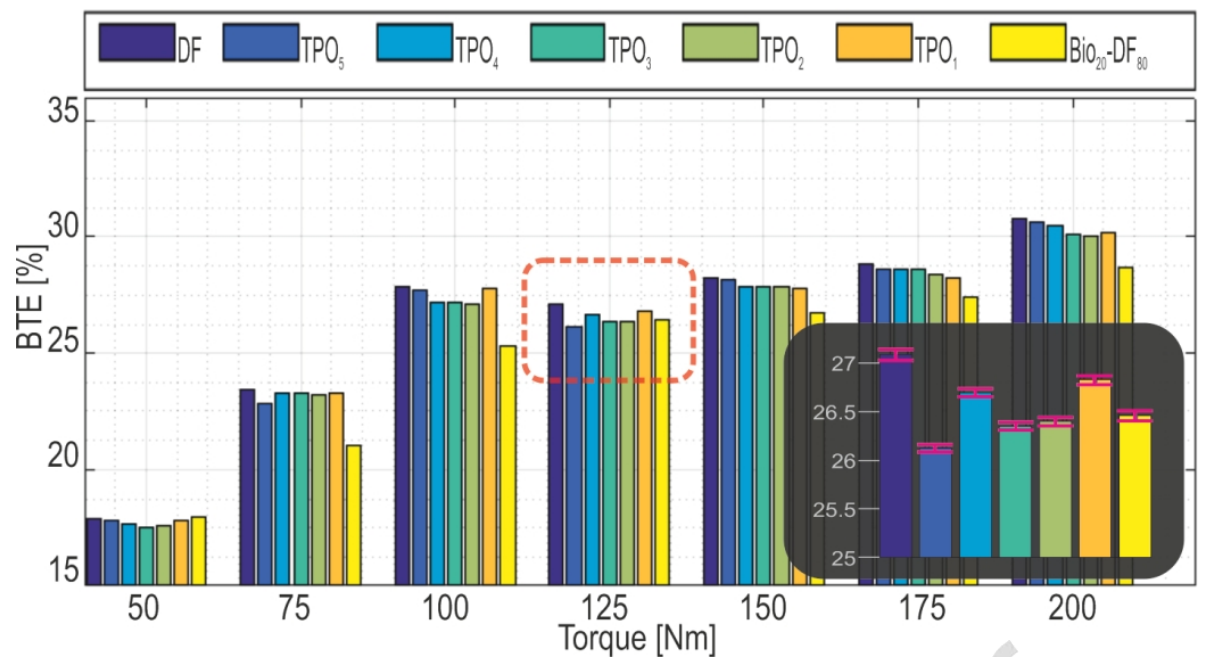

Fig. 13. Brake thermal efficiency; $N=3000 \mathrm{RPM}, \mathrm{Tq}=125 \mathrm{Nm}$. Error bars (for a chosen operating point) denote the maximum uncertainty.

Bearing the above remarks in mind, one can conclude that under the lowest load, for both tested engine-speeds, efficiency differences between the tested biofuel mixtures and diesel are below the level of significance. For higher loads however, the binary mixture of diesel and rapeseed oil showed considerable efficiency deterioration with respect to the diesel reference. For instance, at $3000 \mathrm{rpm}$ and $100 \mathrm{Nm}$ the absolute difference in efficiency was as much as $2.2 \%$ with an average uncertainty of $0.04 \%$. For all TPO samples the efficiency was only slightly lower compared to diesel. For instance, at the same operating point the TPO samples resulted in BTE values ranging from 27.2\% to 27.8\%, while the diesel operation gave the thermal efficiency of $27.9 \%$. There was no clear relationship between the addition of biocomponent in the ternary mixture and efficiency loss. At one operating point, the sample $\mathrm{TPO}_{5}$ (with $30 \% \mathrm{RO}$ ) produced better efficiency than $\mathrm{TPO}_{1}(55 \% \mathrm{RO})$, whereas at other operating points an opposite trend was observed. Nevertheless, the maximum difference between all TPO samples did not exceed $0.6 \%$. At the same time, the maximum difference between a given TPO sample and DF was around 1.2\% ( $\mathrm{TPO}_{4}$ vs DF at $150 \mathrm{Nm}$ and $\left.1500 \mathrm{rpm}\right)$ with an average uncertainty of $0.22 \%$.

Summarizing the above discussion, the obtained TPO samples showed significantly better performance compared to the binary fuel blend with RME. The 5\% addition of pyrolytic oil enables the share of the inexpensive raw biocomponent in diesel fuel to be as much as 55\%, with only slight overall performance deterioration compared to DF. Since a detailed combustion analysis is beyond the scope of the present paper, only brief remarks on the causes of the observed differences in BTE are provided below. For a more detailed analysis of combustion of fuels containing TPO, refer to a different work by the authors [17].

Further insight into the causes of the observed performance differences between diesel, ternary TPO samples and binary sample $\left(\mathrm{Bio}_{20}-\mathrm{DF}_{80}\right)$ can be gained by analyzing the net indicated efficiency trends. For consistency, this is visualised by mapping the differences in net indicated efficiency between diesel and $\mathrm{TPO}_{3}$ in Fig. 14. A corresponding map for the binary Bio20-- $\mathrm{DF}_{80}$ sample is shown in Fig. 15. Note that for the purpose of mapping, the results of the engine-load sweeps at intermediate speeds of 2000 and $2500 \mathrm{rpm}$ are also included. 


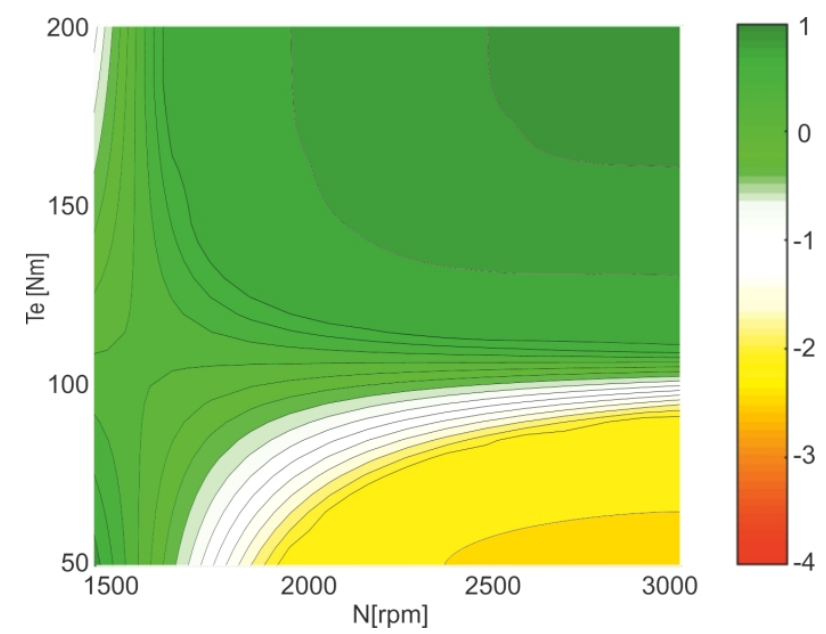

Fig. 14. Delta between net indicated efficiency of the engine operated on $\mathrm{TPO}_{3}$ and $\mathrm{DF}$. The negative values indicate favorable results for DF.
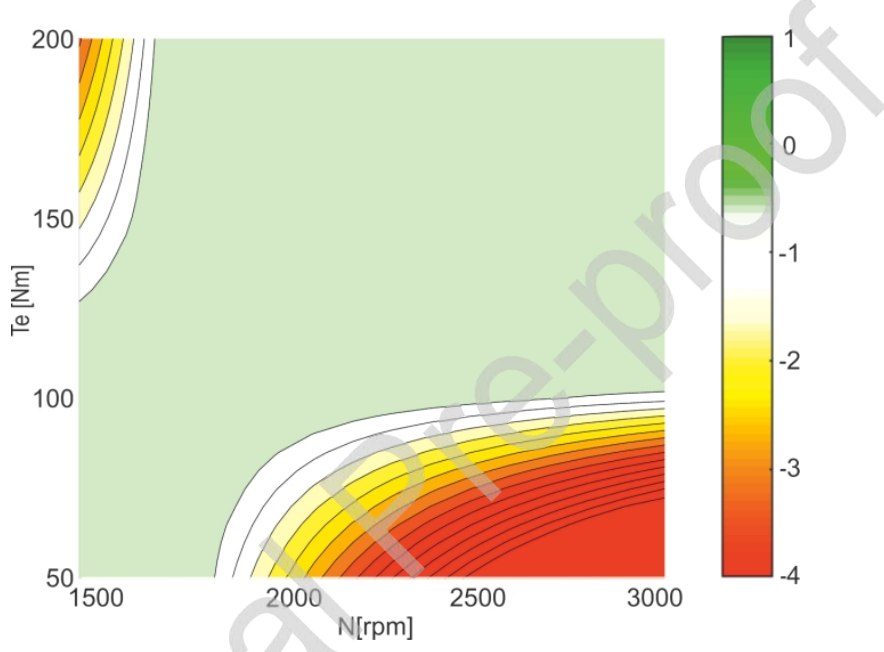

Fig. 15. Delta between net indicated efficiency of the engine operated on $\mathrm{Bio}_{20}-\mathrm{DF}_{80}$ and $\mathrm{DF}$. The negative values indicate favorable results for DF.

Figure 14 indicates that, despite the overall BTE being lower for the $\mathrm{TPO}_{3}$ sample than for diesel, the net indicated efficiency can sometimes slightly favour $\mathrm{TPO}_{3}$. With low engine speeds this occurs at low engine loads, where the efficiency is approximately 1 percentage point (pp) higher than with diesel, with a deteriorating trend towards high loads. The trend is opposite for higher engine speeds, with $\mathrm{TPO}_{3}$ 's partial loads' performance being 2 pp lower than the diesel baseline. Note that the corresponding maps for all TPO samples are in general alike.

The trends in relative indicated efficiency for the $\mathrm{Bio}_{20}-\mathrm{DF}_{80}$ sample shown in Fig. 15 are generally the same as those for the TPO samples shown in Fig. 14. The magnitude of efficiency deterioration is however generally much more significant. In the particularly sensitive regions (low load /high engine speed and high load /low engine speed), the net indicated efficiency is between $3 \mathrm{pp}-4 \mathrm{pp}$ lower than the baseline diesel operation. In other regions of the map, where TPO showed increased performance, the net indicated efficiency for $\mathrm{Bio}_{20} \mathrm{DF}_{80}$ is nearly the same as for the diesel reference.

Analysis of Figs. 14 and 15 suggests that the 5\% TPO addition facilitates good combustion at a wide range of operating points of the engine and for a wide range of biocomponent shares (up to $50 \%$ by volume). Without the TPO addition, only a $20 \%$ admixture of RME to diesel causes significant deterioration of indicated efficiency. Note that the pumping losses were found to be independent of the kind of fuel used. Thus, the deterioration comes from incomplete combustion and worsened combustion phasing of the $\mathrm{Bio}_{20} \mathrm{DF}_{80}$ sample compared to both the diesel reference and TPO samples. Running the engine on $\mathrm{Bio}_{20}-\mathrm{DF}_{80}$ generally increased THC and $\mathrm{CO}$ emissions (refer to the following section for details), but the combustion losses calculated on the basis of both emission factors did not exceed the value of $0.3 \%$ for any of the operating points. Thus, the shifted combustion phasing is suspected to play a vital role in the indicated efficiency changes between $\mathrm{Bio}_{20}-\mathrm{DF}_{80}$ and other tested fuels. More insight into the effect of different biofuels on 
combustion phasing can be found in other works by the authors [17,37, 38].

An interesting observation can be made by comparing Fig. 14, which shows the indicated efficiency for $\mathrm{TPO}_{3}$ (in relation to diesel), with the corresponding BTE values in Figs. 12 and 13. Note that the difference between the net indicated efficiency and BTE can be interpreted as total friction losses due to both mechanical and parasitic resistance. The generally lower values of BTE achieved for the TPO samples at all operating points (Figs. 12 and 13), despite their better results of indicated efficiency (at selected operating points), suggest that friction significantly increased during $\mathrm{TPO}_{3}$ operation compared to the diesel reference. This is explicitly shown in Fig. 16.

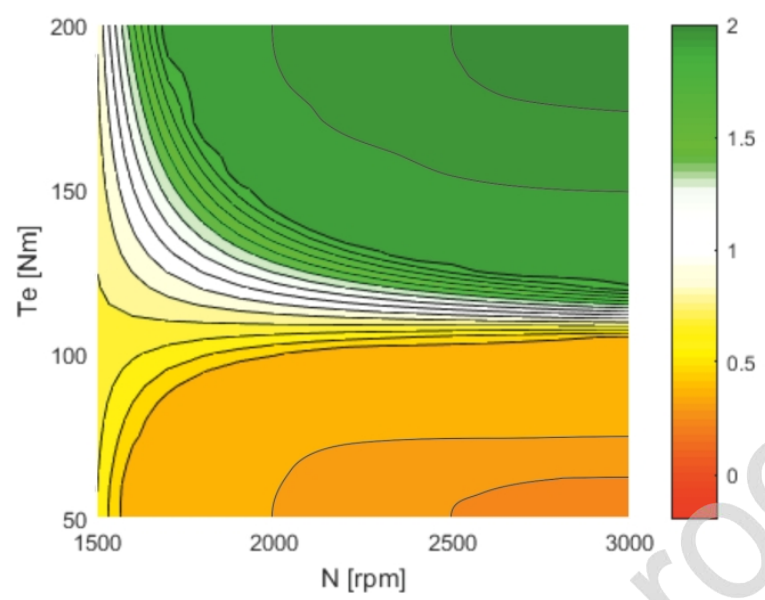

Fig. 16. Delta between friction losses of the engine operated on $\mathrm{TPO}_{3}$ and $\mathrm{DF}$. The negative values indicate lower friction for DF.

Detailed analysis of Fig. 16 reveals a nearly 2 pp increase in friction for the $\mathrm{TPO}_{3}$ sample at high engine loads. At low engine loads the friction increase can hardly be observed. This can be attributed to increased parasitic losses in the fuel injection equipment caused by higher viscosity of the TPO fuels compared with DF (see Table 2 for reference). The friction loss for highly viscous fuels is compounded by their lower heating value (Table 2). With this, more fuel needs to be transferred through the fuel system to attain the same power output. Finally, the TPO samples with the highest biocomponent share exhibit the largest increase in friction. For the same reasons, the increase in friction losses for the ternary mixtures maximizes at high loads and high rpm.

For the $\mathrm{Bio}_{20}-\mathrm{DF}_{80}$ sample the increase in friction is just slightly above the level of significance at higher engine loads (taking into account the accuracy of BTE calculation), which correlates with the fact that its viscosity, density and heating values deviate less from the diesel reference (Table 2). Details of this are presented in Fig. 17 for reference.

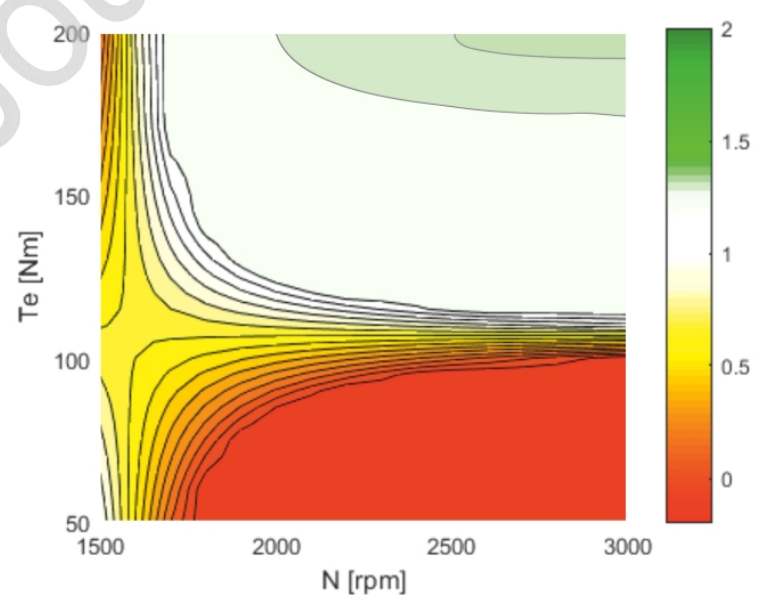

Fig. 17. Delta between friction losses of the engine operated on $\mathrm{Bio}_{20}-\mathrm{DF} 80$ and $\mathrm{DF}$. The negative values indicate lower friction for DF.

The slightly negative values in Fig. 17 at partial loads indicating lower friction for DF can be interpreted as insignificant. For instance, for DF at $50 \mathrm{Nm}$ and $3000 \mathrm{rpm}$, the friction amounts to around $18 \%$ of total energy. Thus, 
the relative friction difference between $\mathrm{Bio}_{20}-\mathrm{DF}_{80}$ and $\mathrm{DF}$ at this particular operating point is lower than $1 \%$. In contrast, the almost 2 pp difference in friction observed in Fig. 16 at high loads accounts for more than a 22\% relative increase in friction losses for $\mathrm{TPO}_{3}$ operation over baseline diesel.

The observations made here are somewhat consistent with the results obtained in the earlier work by Koc and Abdullah [33], who examined a ternary blend of 5\% bio-diesel, 5\% TPO and 90\% DF on a legacy engine with mechanically-driven injection equipment. The above authors noted that at lower engine speeds (from $1000 \mathrm{rpm}$ to 2400 $\mathrm{rpm}$ ), the engine operation on this ternary fuel mixture was characterized by lower BTE values compared to the reference DF sample, while above $2400 \mathrm{rpm}$ the trend was reversed [33]. In turn, the cited research revealed that the blends with increased share of bio-diesel and TPO (10\% each, respectively) resulted in significantly lower BTE values than in the case of mineral fuel at higher engine speeds (above $2000 \mathrm{rpm}$ ). The observed tendency was explained by higher viscosity and density of TPO blends, which - according to the authors - contributed to improper combustion. However, the exact identification of engine losses was not provided in the above-mentioned work.

\subsection{Exhaust emissions}

Exhaust emissions indicators, except for opacity, were presented as concentrations on a volumetric basis. These quantities were chosen because they can be better referred to in-cylinder concentrations and thermal parameters than specific emission factors that are biased by thermal efficiency. The concentrations are thus presented as raw measurement values averaged over the measurement window. The THC concentrations are expressed as $\mathrm{C}_{1}$, as displayed by Flame Ionization Detector.

\subsubsection{Total unburned hydrocarbons}

Emissions of unburned hydrocarbons are the direct result of incomplete combustion of fuels [34]. The reasons for incomplete combustion and formation of unburned hydrocarbons are primarily related to global or local oxygen deficiency and wall/crevice mixture interactions. However, due to the inhomogeneous nature of diesel combustion, mixture formation, fuel vaporization, its composition and, finally, burn rate, should all be considered when clarifying trends in emissions. The complexity of hydrocarbon emission trends for the tested fuels is demonstrated in Fig. 18 and Fig. 19. Comparing the ternary fuel samples with the binary and DF samples, it was noted that significantly lower THC concentrations were generated for the mineral fuel under the tested loads at both engine speeds. Furthermore, it was found that the significantly higher THC emissions were generated at low-load regime for all tested samples, at both engine speeds, which is consistent with the results obtained by Murugan et al. [21] and Bhaskar et al. [47]. The above authors explained that the higher THC emissions observed at low loads resulted from incomplete combustion, caused by the production of locally over-lean mixtures during the longer ignition delay period. Moreover, the THC emission for all analyzed samples gradually decreased between 50 and $150 \mathrm{Nm}$ measurement points (at $1500 \mathrm{rpm}$ ), while above $150 \mathrm{Nm}$ it remained at almost the same level.

It was also observed that at the first two measurement points $(50 \mathrm{Nm}$ and $75 \mathrm{Nm})$ significantly higher amounts of total unburned hydrocarbons were formed by combustion of the ternary blends. This probably resulted from a longer time needed for fuel vaporization and preparation of the combustible mixture, because crude rapeseed oil is mainly composed of fatty acids that consist of long hydrocarbon chains. As a result, the combustion rates of raw oil are too low to provide complete combustion before it is terminated by the dropping temperature during the expansion stroke [48]. The presence of unsaturated hydrocarbons in a distilled fraction of TPO further leads to reduction of combustion rates. Murugan et al. [49] and Kidoguchi et al. [50] pointed out that TPO hydrocarbon chains can turn out to be unbreakable under the conditions of typical diesel combustion. Furthermore, the increased emissions of THC for ternary blends could be related to the creation of an overly premixed (and thus too lean) mixture. This effect was quantified by Kidoguchi et al. [50], who demonstrated a significant increase in THC concentrations at low load for low cetanenumber fuels as a result of increased mixing time.

The above reasoning is supported by the trend in the relative THC emissions shown in Fig. 18. The differences diminish with increasing engine load because the increase in fuel concentration itself reduces the auto-ignition delay, and, additionally, higher combustion temperatures reduce the time of fuel vaporization and thus accelerate the combustion of mixing controlled phase.

Interestingly, the relative THC emissions for $\mathrm{Bio}_{20}-\mathrm{DF}_{80}$ change with engine load, as shown in Fig. 18. Namely, for low load the emissions are substantially lower than for other blends, whereas for higher load the emissions are relatively 
higher. This trend might be associated with wider spray propagation when the fuel contains a biodiesel component. Cosequently, fuel hydrocarbons are concentrated near the combustion chamber walls, enhancing the side-wall effect. Additionally, gaseous fuel penetrates into the crevice volume and is left in an unburned form [51].

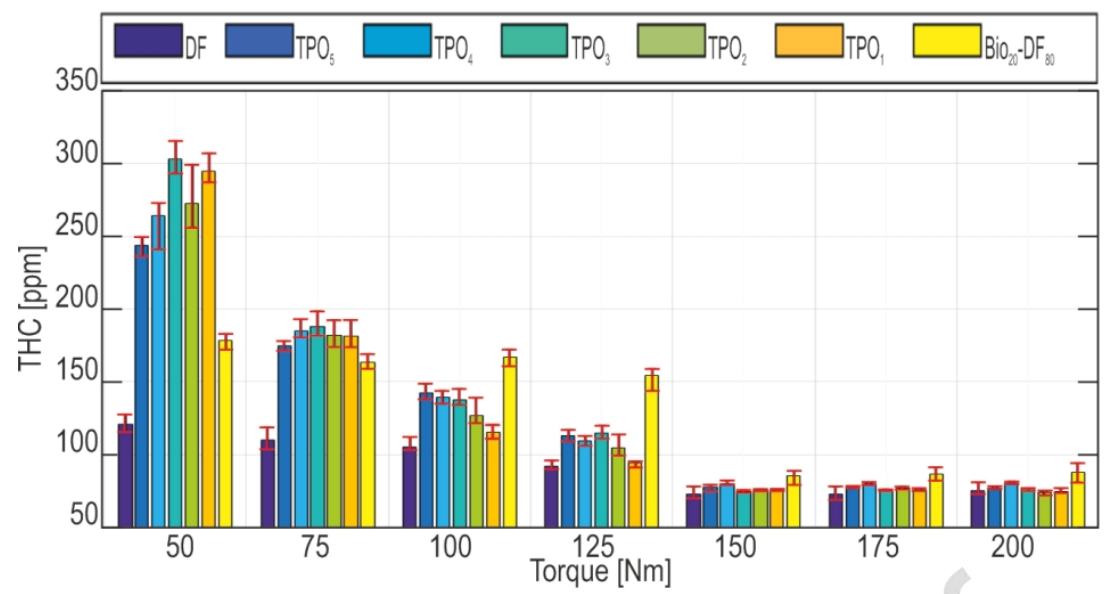

Fig. 18. $T H C$ emissions for tested fuels; $N=1500 \mathrm{rpm}$.

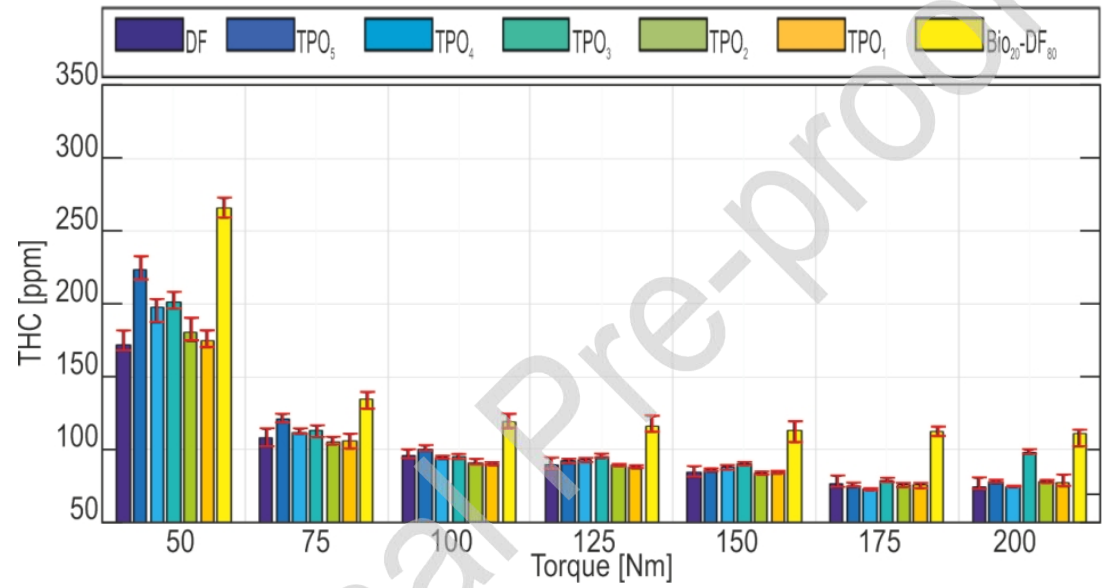

Fig. 19. THC emissions for tested fuels; $N=3000$ rpm.

Comparing THC emissions for the two investigated engine speeds, one cannot neglect the different injection strategies. At $1500 \mathrm{rpm}$, split fuel-injection was realized, whereas at $3000 \mathrm{rpm}$ fuel was injected in a single dose. At the higher speed, the highest THC emissions were achieved for the binary blend independently of engine load, as shown in Fig. 19. This supports the thesis that increased THC emissions for the binary blend result from deeper spray propagation towards the combustion chamber walls. This thesis suggests that in a single dose more fuel is injected at a time, so the propagation distance increases and THC emissions are substantially increased, even for low loads. Under these conditions, however, the emissions produced by ternary blends are comparable to those of diesel fuel.

Though THCs are increased for the TPO samples, in terms of absolute values they are still very low (characteristic for diffusion flame combustion). Note however that aside from the quantitative effect, the composition of HCs may significantly differ for TPO. Here especially the PAHs might be an issue: some of them have been identified as carcinogenic and mutagenic [52]. Williams et al. [16] provided detailed composition of TPO showing total PAH content of $9.2 \%$ where the main constituents were naphthalene, fluorene and phenanthrene and their alkylated derivatives. Although the PAH concentration was approximately three times higher than with typical DF, it did not exceed the limit set by the EN590 standard, which is $11 \%$ on a mass basis. Moreover, composition of TPO depends on feedstock and the pyrolysis process conditions. For example, Frigo et al. [22] reported PAH content of 7.8\%. Finally, it should be noted that in the current study only $5 \%$ admixture of TPO was used, while high fractions of bio-oil did not contain any PAHs.

\subsubsection{Nitrogen oxides}

The main factors determining the level of $\mathrm{NO}_{\mathrm{x}}$ formation in a $\mathrm{CI}$ engine are the temperature of combustion and the availability of oxygen $[30,53]$. However, due to some nitrogen in TPO, the production of $\mathrm{NO}_{\mathrm{X}}$ can be increased for that 
fuel [16]. Intensities of $\mathrm{NO}_{\mathrm{X}}$ production, shown in Figs. 20 and 21, reveal a general trend that the higher the engine load, the higher the emissions of $\mathrm{NO}_{\mathrm{X}}$. This dependence is well-understood and was explained by Sharma and Murugan [30] and Tan et al. [53]. Namely, $\mathrm{NO}_{\mathrm{X}}$ production increases due to the fact that with increasing fuelling rates, the temperature in the combustion chamber increases, creating favorable conditions for thermal $\mathrm{NO}_{\mathrm{X}}$ formation [30].

A comparison of Figs. 20 and 21 reveals an interesting tradeoff. For low-load conditions $(50 \mathrm{Nm})$, the $\mathrm{NO}_{\mathrm{X}}$ concentrations are lower for $1500 \mathrm{rpm}$ than for $3000 \mathrm{rpm}$. However, at high loads the relation is opposite. To explain this behavior, injection strategies should be taken into consideration. The split-injection strategy with fixed pilot injection fuel quantity provides a high fraction of premixed low-temperature combustion which hardly produces $\mathrm{NO}_{\mathrm{X}}$. However, split injection can lead to increased $\mathrm{NO}_{\mathrm{X}}$ production at high loads because the combustion of pilot injection advances the combustion of the main fuel dose, which contributes to higher peak temperatures. These trends are consistent with those observed for peak pressure, shown in Figs. 10 and 11. In contrast, for the single fuel injection at high loads, the $\mathrm{NO}_{\mathrm{X}}$ content is lower than for the split injection due to a high fuel concentration in the flame zone and a higher fraction of fuel burned by diffusion-controlled combustion.

Furthermore, it was observed that at lower loads (from $50 \mathrm{Nm}$ to $100 \mathrm{Nm}$ ) at $1500 \mathrm{rpm}$, the composition of investigated blends did not significantly affected the level of $\mathrm{NO}_{\mathrm{X}}$ emissions, as shown in Fig. 20. In turn, at higher load levels (above $100 \mathrm{Nm}$ ), the ternary blends generated higher amounts of nitrogen oxides, with a clear trend showing that the content of rapeseed oil enhances $\mathrm{NO}_{\mathrm{X}}$ production. This effect can be attributed to two factors: (i) oxygen content in biofuel, and (ii) nitrogen content in TPO. The significant effect of the elementary composition of fuel on $\mathrm{NO}_{\mathrm{X}}$ formation was quantified by Vihar et al. [54]. The fuel-bound nitrogen was identified as a precursor of increased $\mathrm{NO}_{\mathrm{X}}$ emissions from TPO resulting from the fuel NO production mechanism. The above authors also stated that the contribution of fuel mechanism to total $\mathrm{NO}_{\mathrm{X}}$ production increases with engine load due to decreasing dilution combined with lack of the excess air ratio effect. Additionally, Murugan et al. [21] found that the use of higher doses of TPO characterized by significant aromatics content might further lead to increased $\mathrm{NO}_{\mathrm{X}}$ emissions of TPO blends.

Interestingly, for the single-injection case $(3000 \mathrm{rpm})$, there is no clear trend of $\mathrm{NO}_{\mathrm{X}}$ emissions versus tested fuel blends, as shown in Fig. 21. It could be attributed to longer ignition delay and more rapid start of combustion rather than to the split-injection case, as one can observe by comparing Figs. 5 and 6. Such conditions favor thermal $\mathrm{NO}_{\mathrm{X}}$ formation rather than fuel mechanism. As a result, the production of $\mathrm{NO}_{\mathrm{X}}$ was not affected by fuel composition.

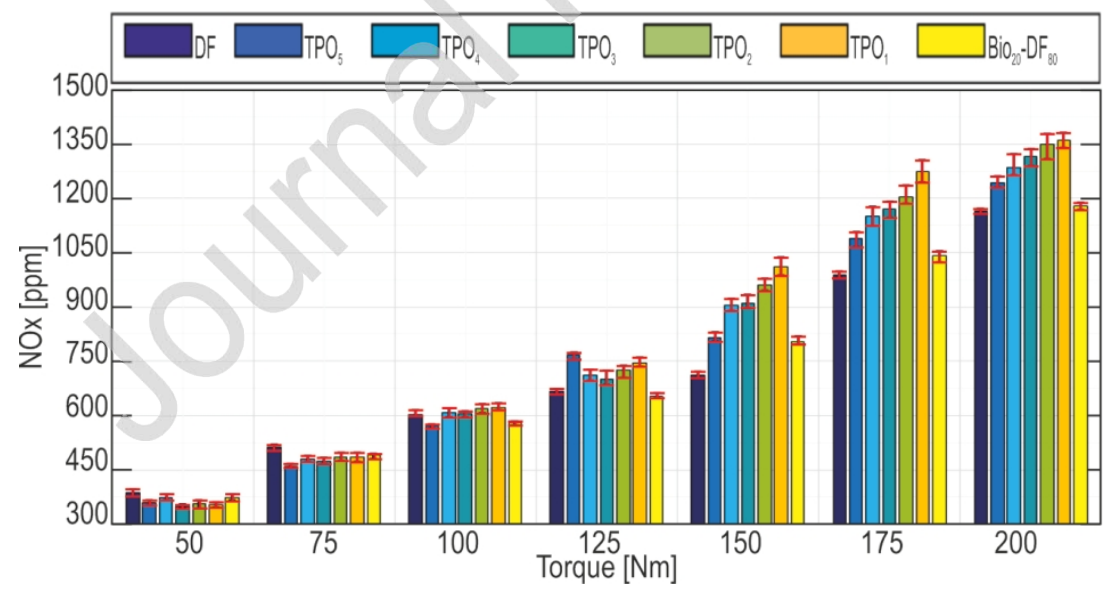

Fig. 20. $\mathrm{NO}_{\mathrm{X}}$ emissions for tested fuels; $\mathrm{N}=1500 \mathrm{rpm}$. 


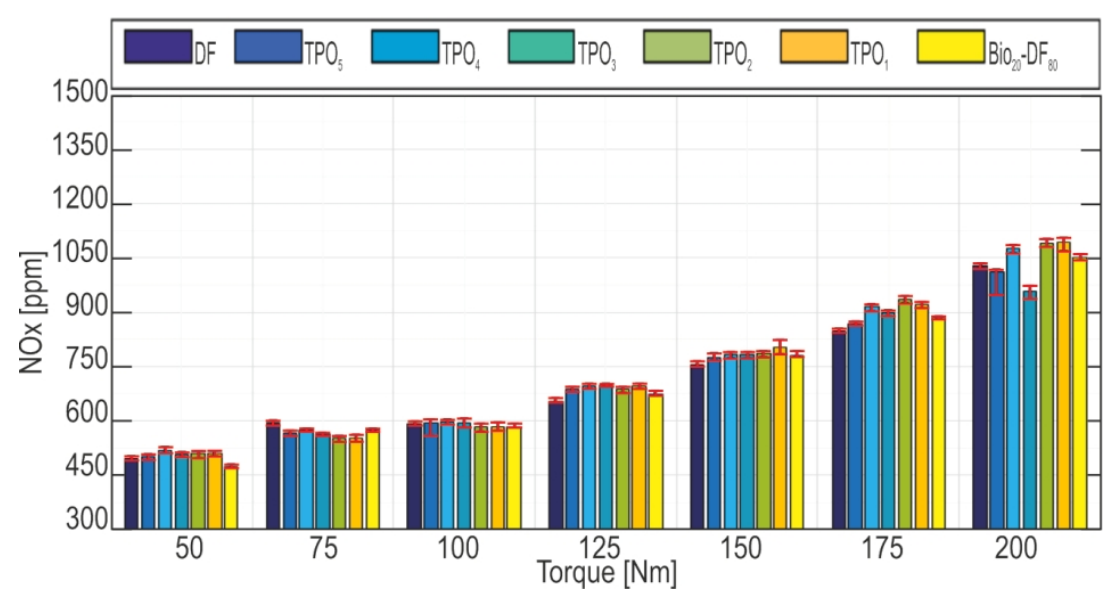

Fig. 21. $\mathrm{NO}_{\mathrm{X}}$ emissions for tested fuels; $\mathrm{N}=3000 \mathrm{rpm}$.

\subsubsection{Carbon monoxide}

An analysis of $\mathrm{CO}$ emissions at $1500 \mathrm{rpm}$ demonstrated a different profile of gas formation in different load ranges, as shown in Figs. 22 and 23. For the lower investigated engine speed (Fig. 22), it can be observed that at lower engine loads $(50-100 \mathrm{Nm})$, the ternary samples are characterized by higher CO emissions in comparison to the binary and DF samples. This trend resembles that observed for THC, shown in Fig. 18, and - similarly to the previous discussion - the increased $\mathrm{CO}$ emissions can be attributed to a longer mixture formation time, which results in the creation of lean premixed mixture areas $[49,50]$. What is more, the blends with a higher DF share examined at 50 and $75 \mathrm{Nm}$ measurement points generated higher emissions of $\mathrm{CO}$, while at higher loads (100-125 Nm) the opposite tendency was observed. In contrast, at both $125 \mathrm{Nm}$ and $200 \mathrm{Nm}$ operating points, higher CO emission was observed for the DF sample and binary blend. Between the aforementioned engine-load points, the concentrations for all tested fuels were nearly the same. Moreover, it should be noted that the emissions were generally lower than for other engine loads. This non-monotonic trend in $\mathrm{CO}$ emissions results from a balance between the combustion temperature and the local excess air ratio. In other words, at low-load regime, the combustion temperature is low and CO oxidation can be terminated. In contrast, at high loads the temperature is high enough, but oxygen deficiency can occur locally.

The above reasoning is also supported by the results for $3000 \mathrm{rpm}$. In the latter case, however, the minimum CO emissions are observed for the $100 \mathrm{Nm}$ load. This is plausible because in contrast to the $1500 \mathrm{rpm}$ operation, the injection is single in this case, and thus fuel is more concentrated in the combustion chamber.

In general, for higher loads at $1500 \mathrm{rpm}$ and for the entire load range at $3000 \mathrm{rpm}$, the ternary samples show a noticeable trend that as the fuel's RO content increases, the lower the CO emissions become. It should be noted that among the tested fuel components, $\mathrm{RO}$ contain the most oxygen. These observations are in agreement with the findings of Xiao et al. [55], who proved that fuel blends with higher oxygen content produce lower CO emissions. However, it should be noted that in low-load regime and at $1500 \mathrm{rpm}$ the opposite tendency was observed. The discrepancy between the results for the two engine speeds can result from different mixture formation strategies. It could be concluded that the oxygen content in fuel reduces $\mathrm{CO}$ concentration if it originates from high fuel concentrations and locally rich mixture. For a more-premixed mixture (less fuel and split injection), the effect is opposite, because the oxygen content in fuel makes the mixture leaner and thus reduces its combustion temperature. 


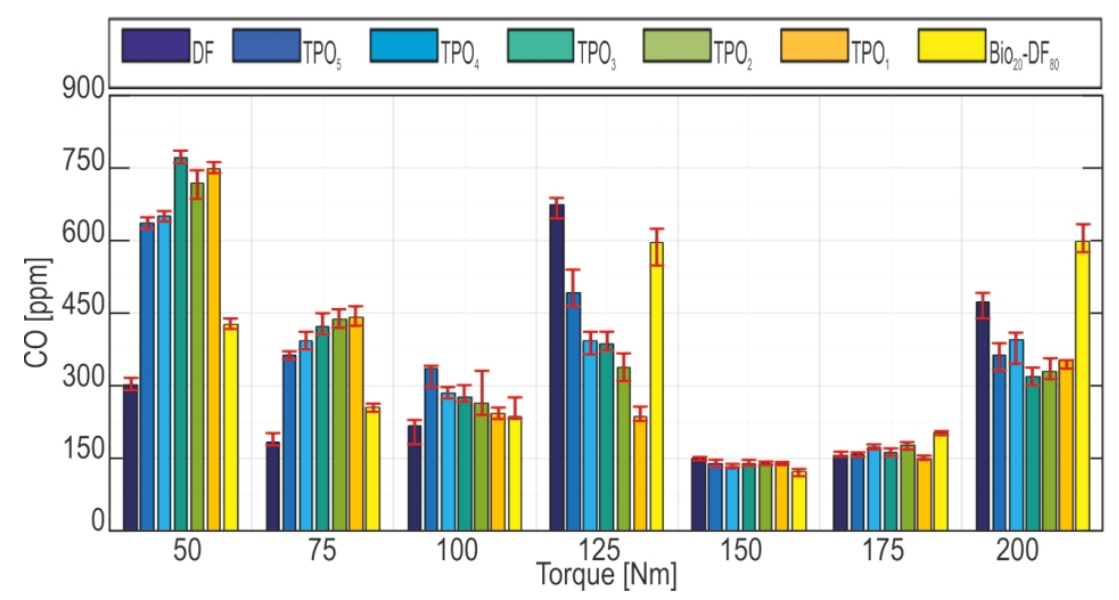

Fig. 22. $\mathrm{CO}$ emission for tested fuels; $\mathrm{N}=1500 \mathrm{rpm}$.

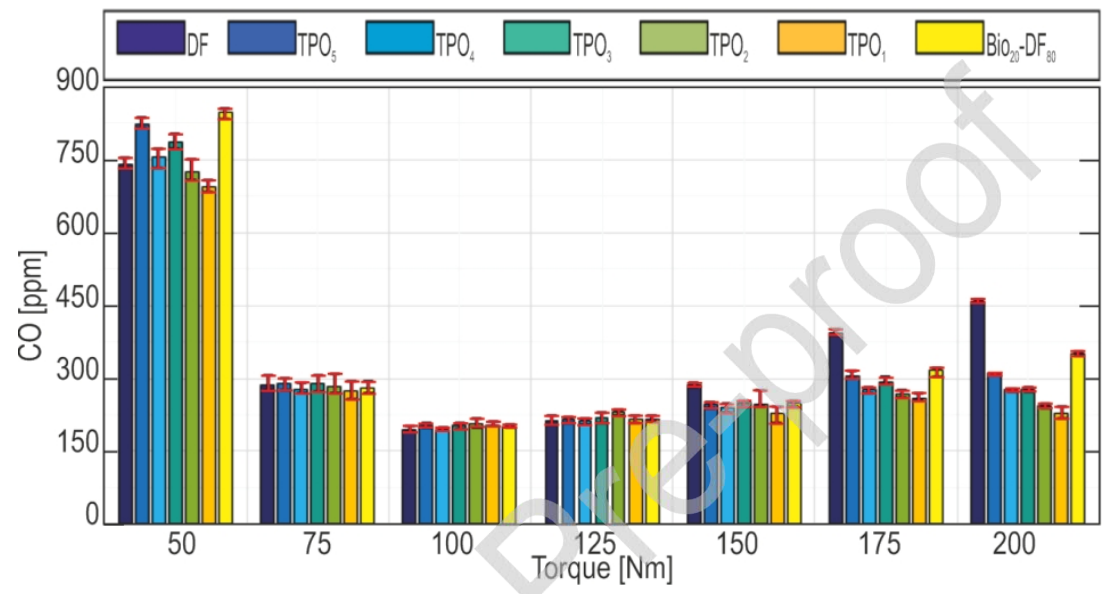

Fig. 23. CO emission for tested fuels; $N=3000 \mathrm{rpm}$.

\subsubsection{Exhaust gas opacity}

The investigations showed that in most cases, the soot produced from diesel fuel combustion, represented in the results by EGO, is higher than that from the blends containing biofuel components, as shown in Figs. 24 and 25 . These results correlate with the findings of Corosini et al. [48], who found that less soot is produced in the combustion of biofuels due to oxygen content in the fuel. The exception was observed only at 50 and $75 \mathrm{Nm}$ measurement points for $1500 \mathrm{rpm}$ speed, where the EGO from DF was similar to the $\mathrm{TPO}_{1}-\mathrm{TPO}_{3}$ blends, as shown in Fig. 24. However, under these conditions the binary blend was characterized by a significantly lower EGO. Another exception can be noted at $150 \mathrm{Nm}$ load point and $1500 \mathrm{rpm}$, where, generally, a significant reduction in EGO is observed for all tested samples. This result can be attributed to the change of injection strategy at this measurement point, as shown in Fig. 7, i.e. the advance of main fuel injection. A further increase in opacity despite the advanced injection is a result of increasing fuel concentration [31]. At the maximum load for $1500 \mathrm{rpm}$, the higher EGO was observed for the DF sample and binary blend, in contrast to other cases. As for the ternary blends, it was found that at $1500 \mathrm{rpm}$ they generated a varied EGO at individual measurement points. At lower loads (50 and $75 \mathrm{Nm})$, the blends with higher rapeseed oil contents generated a higher EGO than the mixtures with lower contents of this component. In turn, at 100 and $125 \mathrm{Nm}$ measurement points, the trend was opposite, whereas at higher loads no clear trend could be detected. In the case of engine tests conducted at $3000 \mathrm{rpm}$, it was observed that with increasing load (from 50 to $200 \mathrm{Nm}$ ), the EGO concentration gradually increased for all analyzed samples, as shown in Fig. 25. Moreover, at higher loads, for all blends except for Bio20-DF80, one can observe a trend that greater content of biofuel component leads to lower opacity. 


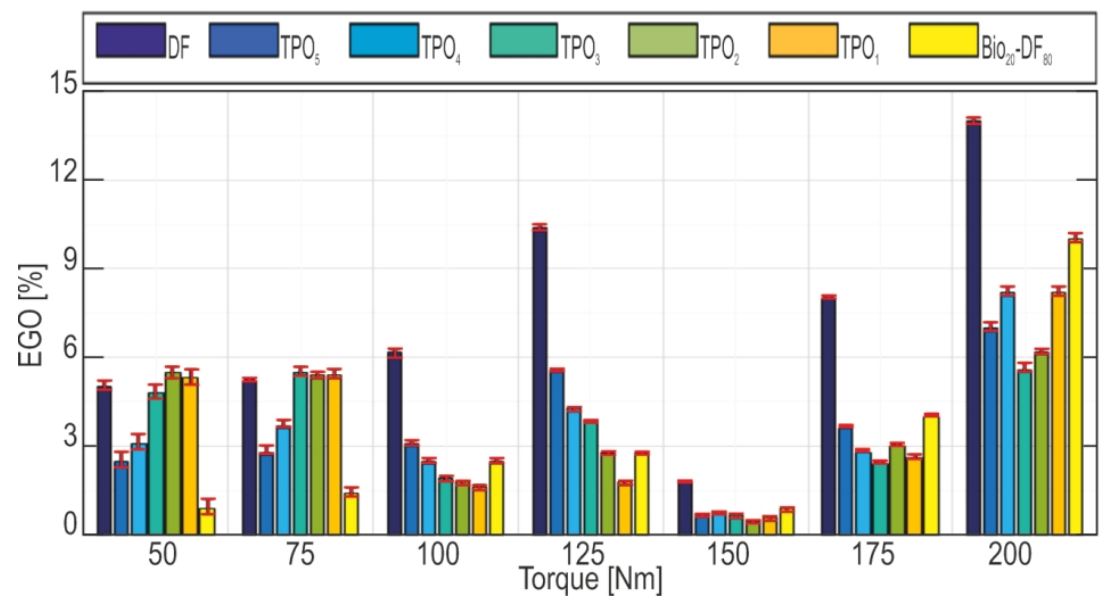

Fig. 24. $E G O$ for tested fuels; $N=1500 \mathrm{rpm}$.

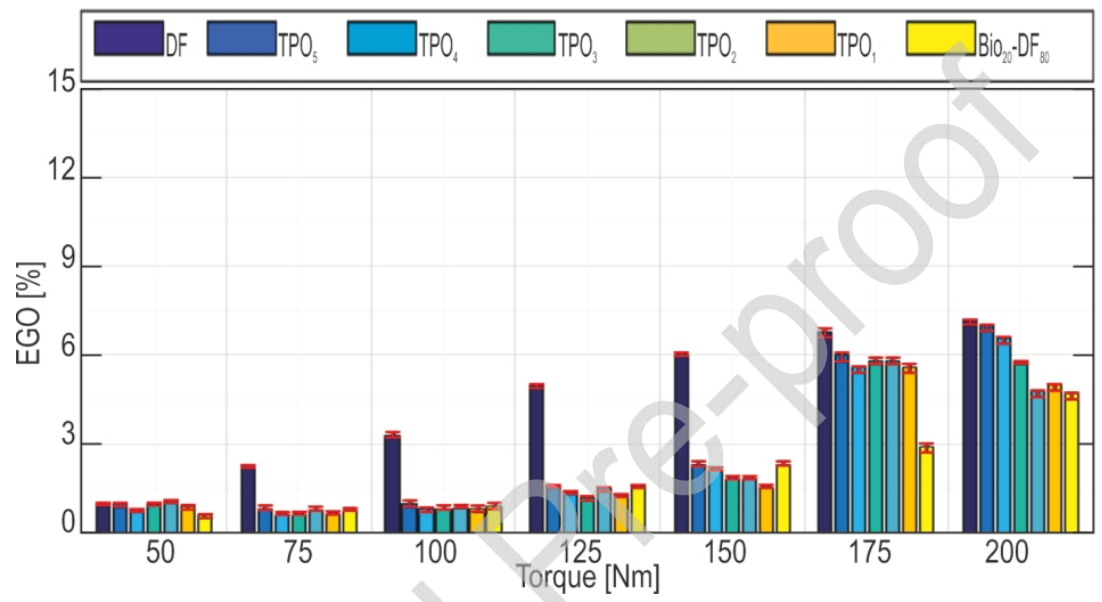

Fig. 25. EGO for tested fuels; $N=3000 \mathrm{rpm}$.

Due to the broad scope of the present research, PM emissions through direct gravimetric measurements were not considered here. For a conventional CI engine, however, due to the fact that HC emission is relatively low, EGO is almost linearly correlated with PM concentrations [56]. To this, trend-wise observations are considered transferable and the generally lower PM content is recognized for oxygenated fuels. Particular differences between subsequent biofuel samples are generally not constant and both EGO and PM mass is influenced rather by the net effect of physical properties of the fuel on combustion parameters. The differences in chemical composition of the fuel, including the increased sulphur content of the TPO, do not translate towards distinguishable effect on EGO or PM mass. However, more profound differences máy occur in particulates size distribution when fuels of different feedstock are used [57, 58]. This issue might affect the feasibility of crude oils with TPO addition as drop-in fuels and should be addressed in dedicated research.

\subsection{Discussion and future outlook}

Since the research scope of this work is broad and exploratory, it is not strictly aimed at providing insight into the actual phenomena causing differences in efficiency and emissions between individual fuel samples. However, the study's results do point towards some general observations that bridge the knowledge gap and indicate further research directions.

1. When using highly viscous fuel components (as raw RO), parasitic losses in the fuel injection equipment play an increasingly important role in the overall energy balance of the engine. This can contribute to as much as $2 \%$ loss at high load operation for fuel samples with high shares of RO. To mitigate these losses, further research should be conducted into an optimized fuel composition which takes into account the flashpoint-viscosity tradeoff. 
2. The methyl ester-based biofuel, without TPO addition, exhibited significant deterioration in indicated efficiency, especially at high engine speeds and low loads. The addition of biocomponent alone is known to cause a significant delay in auto-ignition and extended combustion duration. The samples with TPO showed considerable efficiency improvement over $\mathrm{Bio}_{20}-\mathrm{DF}_{80}$ despite higher shares of unrefined biocomponent. This indicates that in terms of efficiency, adding TPO to fuel produces benefits derived from the mixture's improved auto-ignition properties and burn rate.

3. The study demonstrated that the effects of ternary fuel composition on emissions are complex, with several contributing factors including spray characteristics, mixture and temperature distribution and the fuel's physicochemical properties. The relationships between fuel properties and emissions greatly depend on the mixture formation strategy that is used (single injection or split injection). Consequently, research should be continued by designing controlled experiments investigating the sensitivity of exhaust emissions to fuel-injection strategies under the same conditions.

4. The detailed speciation of THCs and PM size distribution should be further researched, as reported to be significantly different for TPO admixed fuels, compared to other alternatives. In particular, the presence of specific carcinogenic species (PAHs) can influence the feasibility of developed fuels and should be addressed. For TPO admixed fuels, this is foreseen in a dedicated endeavor and covered together with other relevant legislative emission components, like $\mathrm{N}_{2} \mathrm{O}$ which can majorly affect the GHG footprint.

5. In the study we postulate that direct use of cold-pressed rapeseed oil as bio component admixed with distilled tyre pyrolytic oil could be an energy-efficient alternative to commonly considered methyl ester-based mixtures. Though in-depth analysis of this assumption was not performed at this stage, there are a number of convincing arguments to support it. Note, that the costs of FAME produced form conventional materials can be even $50 \%$ higher than fossil diesel (without taxes and additional costs) [59]. Furthermore, the market cost of eatable-grade rapeseed oil is around $20 \%$ lower than the cost of diesel, giving a solid advantage for the main fuel component considered in this study. Regarding TPO, although its production is energetically demanding, it is fully sustainable due to the off-pyrolytic gases [60]. A recent pilot project on technological and economic feasibility of a 40,000 t/y TPO pyrolysis plant reported the production costs $40 \%$ lower than diesel market prices [60]. Although these arguments demonstrate a clear economic advantage over FAME and mineral fuel, a full techno-economic feasibility study should be conducted. It should include feedstock availability, well-to-wheel economy and emission factors of the new fuels, comparing them with other feasible alternatives.

6. Finally, even a small addition of TPO caused the fuel's sulphur content to exceed the limit for automotive-grade fuels $(10 \mathrm{mg} / \mathrm{kg}$ according to EN 590). Desulphurisation should be included in the TPO-based additive production to mitigate this issue. The above arguments on production costs suggest that there is sufficient room for further postprocessing of the TPO, while maintaining its economic feasibility as a fuel component.

\section{Conclusions}

This study investigated whether raw vegetable oil can be used as an inexpensive fuel biocomponent for modern diesel engines if a small fraction of distilled TPO is also used as an additive. Different mixtures of DF and RO with 5\% addition of distilled TPO were subjected to engine tests. Note that fuel samples with TPO content above $5 \%$ or RO fractions lower than $30 \%$ did not satisfy the handling safety criterion for diesel engine fuels (flash point above $53{ }^{\circ} \mathrm{C}$ ), and so were therefore excluded. Additionally, pure DF and DF with a $20 \%$ addition of rapeseed methyl ester $\left(\mathrm{Bio}_{20^{-}}\right.$ $\mathrm{DF}_{80}$ ) were examined as reference fuels.

General conclusions regarding efficiency and emissions confirm the main thesis of this work, showing that TPO addition allows the use of fuels with large shares of unrefined biocomponent. These conclusions can be formulated as follows:

1. On the factory engine-maps the use of fuel samples with up to $55 \%$ of RO and $5 \%$ of TPO led to only minor deterioration of brake thermal efficiency when compared to that obtained for DF. The maximum deterioration did not exceed $1.2 \%$, with no significant trends over the operating regime nor for the fuel mixtures containing TPO. In contrast, the reference biofuel $\mathrm{Bio}_{20}-\mathrm{DF}_{80}$, without $\mathrm{TPO}$ but with a transesterified biocomponent, showed efficiency deterioration of above $2 \%$ under the same conditions.

2. No abnormal combustion or misfire was observed for any of the tested fuels. The coefficient of variation in IMEP did not exceed the commonly accepted limit of 5\% at any operating point. A further increase in the RO share above 
$50 \%$ was mainly limited by significantly reduced heating value of the fuel, preventing achievement of full-load characteristics due to fuel injection equipment limitations.

3. THC and CO exhaust concentrations significantly increased for the ternary mixtures compared to DF, but only at low load and split fuel injection at $1500 \mathrm{rpm}$ (as much as 3-fold increase at near-idle load). Note that the reference $\mathrm{Bio}_{20}-\mathrm{DF}_{80}$ fuel suffered from the same drawback, and also performed worse in terms of combustion efficiency in all operating conditions.

4. Elevated $\mathrm{NO}_{\mathrm{X}}$ emission is an inherent drawback of using oxygenated fuels. The tested fuels, however, exhibited increased $\mathrm{NO}_{\mathrm{X}}$ concentrations (above the level of significance) only at high load and low engine-speed regime. This region of the operating map is characterized by high combustion temperatures and long residence times, and thus is particularly challenging for mitigation of engine-out emissions. Under such conditions, the increase in $\mathrm{NO}_{\mathrm{X}}$ emissions almost linearly corresponded to the increased biocomponent share in the fuel. The maximum increase of $25 \%$ over the baseline diesel $\mathrm{NO}_{\mathrm{X}}$ emissions was noted for the ternary fuel sample containing $55 \%$ of $\mathrm{RO}$.

\section{Acknowledgements}

The assistance of Magdalena Jung from Lublin University of Technology and David Wilcox with the final editing of the paper is gratefully acknowledged.

\section{References}

[1] Olivier JGJ, Peters JAHW. Trends in global CO2 and total greenhouse gas emissions: 2018 report. PBL Netherlands Environmental Assessment Agency, The Hague 2018.

[2] World Energy Resources 2015. Available on: http:/www.worldenergy.org/wp-content/uploads/2016/10/World-Energy Resources-Full-report-2016.10.03.pdf.

[3] Mikulski M, et al. Public final report - Methanol as an alternative fuel for vessels, Maritime Knowledge Centre, Netherlands 2018. Available on: https://www.mkc-net.nl/library/documents/957/download/.

[4] Verhelst S, Turner JWG, Sileghem L, Vancoillie J. Methanol as a fuel for internal combustion engines. Progress in Energy and Combustion Science 2019; 70:43-88. https://doi.org/10.1016/j.pecs.2018.10.001.

[5] Bergthorson JM, Thomson MJ. A review of the combustion and emissions properties of advanced transportation biofuels and their impact on existing and future engines. Renewable and Sustainable Energy Reviews 2015; 42:1393-1417.

[6] Koszalka G, Hunicz J, Niewczas A. A comparison of performance and emissions of an engine fuelled with diesel and biodiesel, SAE International Journal of Fuels and Lubricants 2010; 3(2): 77-84. http://doi.org/10.4271/2010-01-1474.

[7] Esteban B, Baquero G, Puig R, Riba JR, Rius A. Is it environmentally advantageous to use vegetable oil directly as biofuel instead of converting it to biodiesel? Biomass Bioenergy 2011;35(3):1317-1328. http://doi.org/10.1016/j.biombioe.2010.12.025.

[8] Hossain AK, Davies PA. Plants oils as a fuels for compression ignition engines: a technical review and life-cycle analysis. Renewable Energy 2010; 35(1):1-13. http://doi.org/10.1016/j.renene.2009.05.009.

[9] Ortner ME., Müller W, Schneider I, Bockreis A. Environmental assessment of three different utilization paths of waste cooking oil from households. Resources, Conservation and Recycling 2016; 106:59-67. http://doi.org/10.1016/i.resconrec2015.11.007.

[10] Izdebski W, Jakubowski Z, Skudlarski J, Zając S, Evteevich Maznev G, Aleksandrovna Zaika S. Status and prospects of rapeseed production in Poland and Ukraine in terms of transportation biofuels production. Zeszyty Naukowe Szkoły Głównej Gospodarstwa Wiejskiego w Warszawie. 2014;14:80-88. ISSN 2081-6960 (in Polish).

[11] Ratnasari, DK, Nahil, MA, Williams, PT, Catalytic pyrolysis of waste plastics using staged catalysis for production of gasoline range hydrocarbon oils. Journal of Analytical and Applied Pyrolysis 2017; 124:631-637.

[12] Czajczyńska D, Krzyżyńska R, Jouhara H, Spencer N. Use of pyrolytic gas from waste tire as a fuel: A review. Energy 2017; 134: 1121-1131. http://doi.org/10.1016/j.energy.2017.05.042.

[13] Antoniou NA, Zorpas AA. Quality protocol and procedure development to define end-of-waste criteria for tire pyrolysis oil in the framework of circular economy strategy. Waste Management 2019; 95: 161-170. http://doi.org/10.1016/j.wasman.2019.05.035.

[14] Misra RD, Murthy MS. Straight vegetable oils usage in a compression ignition engine -review. Renewable and Sustainable Energy Reviews 2010; 14(9):3005-3013. http://doi.org/10.1016/j.rser.2010.06.010.

[15] Raheman, H, Phadatare, AG. Diesel engine emissions and performance from blends of karanja methyl ester and diesel. Biomass and Bioenergy 2004; 27(4):393-397. http://doi.org/10.1016/j.biombioe.2004.03.002.

[16] Williams PT, Bottrill RP, Cunliffe AM. Combustion of tyre pyrolysis oil, Process Safety and Environmental Protection 1998; 76(4): 291-301. http://doi:10.1205/095758298529650.

[17] Ambrosewicz-Walacik M, Wierzbicki S, Mikulski M, Podciborski T. Ternary fuel mixture of diesel, rapeseed oil and tyre pyrolytic oil suitable for modern CRDI engines. Transport 2018; 33 (3): 727-740. 
[18] Ikura M, Stanciulescu M, Hogan E. Emulsification of pyrolysis derived bio-oil in diesel fuel. Biomass and Bioenergy 2003; 3:22-232. http://doi.org/10.1016/S0961-9534(02)00131-9.

[19] Bridgwater AW, Canales AJA 2013. Bio-fuel composition and method for manufacture of bio-fuel composition. WO 2013027050 A1, Aston University. http://www.google.com/patents/WO2013027050A1?cl=en22.

[20] Mulimani Vm.H, Navindgi MC. An experimental investigation of DI Diesel engine fuelled with emulsions of mahua bio-oil. International Journal of Science and Research 2015; 6(1): 6-391.

[21] Murugan S, Ramaswamy MC, Nagarajan G. The use of tyre pyrolysis oil in diesel engines. Waste Management 2008a; 28(12): 2743-2749. http://doi.org/10.1016/j.wasman.2008.03.007.

[22] Frigo S, Seggiani M, Puccini M, Vitolo S. Liquid fuel production from waste tyre pyrolysis and its utilisation in a Diesel engine. Fuel 2014; 116:399-408. http://doi.org/10.1016/j.fuel.2013.08.044.

[23] Hürdoğan E, Ozalp C, Kara O, Ozcanli M. Experimental investigation on performance and emission characteristics of waste tire pyrolysis oil-blends in a diesel engine. International Journal of Hydrogen Energy 2016; 42(36): 23373-23378. http://doi.org/10.1016/j.ijhydene.2016.12.126.

[24] Uyumaz A., et al., Production of waste tyre oil and experimental investigation on combustion, engine performance and exhaust emissions, Journal of the Energy Institute 2018; http://doi.org/10.1016/j.joei.2018.09.001.

[25] Martínez JD, Rodríguez-Fernández J, Sánchez-Valdepeñas J, Murillo R. Performance and emissions of an automotive diesel engine using a tire pyrolysis liquid blend. Fuel 2014; 115: 490-99. http://doi.org/10.1016/j.fuel.2013.07.051.

[26] Shahir, V.K., et al. Experimental investigations on the performance and emission characteristics of a common rail direct injection engine using tyre pyrolytic biofuel. Journal of King Saud University - Engineering Sciences 2018; http://doi.org/10.1016/j.jksues.2018.05.004.

[27] Bodisco TA, Rahman SMA, Hossain FM, Brown RJ. On-road NOx emissions of a modern commercial light-duty diesel vehicle using a blend of tyre oil and diesel. Energy Reports 2019; 5: 349-356. http://doi.org/10.1016/j.egyr.2019.03.002.

[28] Murugan S, Ramaswamy MC, Nagarajan G. Performance, emission and combustion studies of DI diesel engine using distilled tyre pyrolysis oil-diesel blends. Fuel Processing Technology 2008b; 89(2): 152-159. http://doi.org/10.1016/j.fuproc.2007.08.005.

[29] Doğan O, Çelik MB, Özdalyan B. The effect of tire derived fuel/diesel fuel blends utilization on diesel engine performance and emissions. Fuel 2012; 95: 340-346. http://doi.org/10.1016/j.fuel.2011.12.033.

[30] Sharma A, Murugan S. Investigetion on the behaviour of a DI diesel engine fueled with jatropha methyl esters (JME) and tyre pyrolysis oil (TPO) blends. Fuel 2013; 108:699-708. http://doi.org/10.1016/j.fuel.2012.12.042.

[31] Sharma A, Murugan S. Effect of blending waste tyre derived fuel on oxidation stability of biodiesel and performance and emission studies of a diesel engine. Applied Thermal Engineering 2017; 118: 265-375. http://doi.org/10.1016/j.applthermaleng.2017.03.008.

[32] Koc AB, Abdullah MK, Schumacher LG, Borgelt S Exhaust emissions of a 4-cylinder diesel engine fuelled with biodiesel, tire oil and diesel fuel blends. American Society of Agricultural and Biological Engineers, Pittsburgh, Pennsylvania, June 20 - June 23 2010. http://dx.doi:10.13031/2013.29865.

[33] Koc AB, Abdullah M. Performance of a 4-cylinder diesel engine running on tire oil-biodiesel-diesel blend. Fuel Processing Technology 2014; 188:264-269. http://doí.org/10.1016/j.fuproc.2013.09.013.

[34] Murugan S, Ramaswamy MC, Nagarajan G. A comparative study on the performance, emission and combustion studies of a DI diesel engine using distilled tyre pyrolysis oil-diesel blends. Fuel 2008c; 87(10-11): 2111-2121. http://doi.org/10.1016/j.fuel.2008.01.008.

[35] Ambrosewicz-Walacik M, Wierzbicki S, Mikulski M, Podciborski T. Ternary fuel mixture of diesel, rapeseed oil and tire pyrolytic oil suitable for modern CRDI engines. Transport 2018; 33(3): 727-740. http://doi.org/10.3846/transport.20185163.

[36] Ambrosewicz-Walacik M, Danielwicz T. Pyrolytic oil and petroleum fractions obtained by pyrolysis of vehicle tires as an energy sources for compression-ignition engines. Combustion Engines 2015; 162(3): 952-957.

[37] Mikulski M, Duda K, Wierzbicki S. Performance and emissions of a CRDI diesel engine fuelled with swine lard methyl estersdiesel mixture. Fuel 2016; 164: 206-219. http://doi.org/10.1016/j.fuel.2015.09.083.

[38] Duda K, Wierzbicki S, Śmieja M, Mikulski M. Comparison of performance and emissions of a CRDI diesel engine fuelled with biodiesel of different origin. Fuel 2018; 212: 202-222. http://doi.org/10.1016/j.fuel.2017.09.112.

[39] Kline SJ, McClintock FA. Describing uncertainties in single-sample experiments. Mechanical Engineering 1953; 75(1): 3-8.

[40] Mikulski M, Wierzbicki S, Piętak A. Zero-dimensional 2-phase combustion model in a dual-fuel compression ignition engine fed with gaseous fuel and a divided diesel fuel charge. Eksploatacja i Niezawodnosc - Maintenance and Reliability 2015; 17(1): $42-48$.

[41] Mikulski M, Wierzbicki S, Piętak A. Numerical Studies on Controlling Gaseous Fuel Combustion by Managing the Combustion Process of Diesel Pilot Dose in a Dual-Fuel Engine. Chemical and Process Engineering 2015; 36(2): $225-238$. http://doi.org/10.1515/cpe-2015-0015.

[42] Monyem A, Van Gerpen JH. The Effect of Biodiesel Oxidation on Engine Performance and Emissions. Biomass and Bioenergy, 2001; 20(4): 317-325. http://doi.org/10.1016/S0961-9534(00)00095-7. 
[43] Mohan B, Yang W, Chou SK. Fuel Injection Strategies for Performance Improvement and Emissions Reduction in Compression Ignition Engines - A Review. Renewable and Sustainable Energy Reviews, 2013; 28: 664-676.. http://doi.org/10.1016/j.rser.2013.08.051.

[44] Yang, Li Ping, Shun Liang Ding, Grzegorz Litak, En Zhe Song, and Xiu Zhen Ma. Identification and Quantification Analysis of Nonlinear Dynamics Properties of Combustion Instability in a Diesel Engine. Chaos, 2015. http://doi.org/10.1063/1.4899056.

[45] Hellström, E, Stefanopoulou, AG and Jiang, L. Cyclic Variability and Dynamical Instabilities in Autoignition Engines with High Residuals. IEEE Transactions on Control Systems Technology, 2013. http://doi.org/10.1109/TCST.2012.2221715.

[46] Hunicz, J. Cycle-by-cycle variations in autonomous and spark assisted homogeneous charge compression ignition combustion of stoichiometric air-fuel mixture. International Journal of Spray and Combustion Dynamics 2018; 10(3): 231-243, http://doi.org/10.1177/1756827718763564.

[47] Bhaskar K, Sassykova LR, Prabhahar M, Sendilvelan S. Effect of dimethoxy-methane (C3 H8 O2) additive on emission characteristics of a diesel engine fueled with biodiesel. International Journal of Mechanical and Production Engineering Research and Development 2018; 8(1):399-406. http://doi.org/10.24247/ijmperdfeb201844.

[48] Corsini A, Marchegiani A, Rispoli F, Sciulli F, Venturini P. Vegetable oils as a fuel in Diesel engine. Engine performance and emissions. Energy Procedia 2015; 81: 942-949. http://doi.org/10.1016/j.egypro.2015.12.151.

[49] Murugan S, Ramaswamy MC, Nagarajan G. Running a diesel engine with higher concentration TPO-DF. Proceedings of the National Conference of Research Scholars in Mechanical Engineering, IIT Kanpur 2007.

[50] Kidoguchi Y, Yang C, Kato R, Miwa K. Effects of fuel cetane number and aromatics on combustion process and emissions of a direct injection diesel engine. JSAE Review 2000; 21(4): 469-475. http://doi.org/10.1016/S0389-4304(00)00075-8.

[51] Nagaranjan G. Renganarayanan S, Rao AN. Emission and performance characteristics of neat ethanol fuelled DI diesel engine. International Journal of Ambient Energy 2002; 23(3): 149-158. http://doi.org/10.1080/01430750.2002.9674883.

[52] Claxton LD. The history, genotoxicity and carcinogenicity of carbon-based fuels and their emissions: Part 4 - Alternative fuels. Mutation Research - Reviews in Mutation Research 2015; 763: 86-102. http://doi.org/10.1016/j.mrrev.2014.06.003.

[53] Tan P, Hu Z, Lou D, Li Z. Exhaust emissions from a light-duty diesel engine with Jatropha biodiesel fuel. Energy 2012; 39(1): 356-362. http://doi.org/10.1016/j.energy.2012.01.002.

[54] Vihar R, Seljak T, Rodman Oprešnik S, Katrašnik T. Combustion characteristics of tire pyrolysis oil in turbo charged compression ignition engine, Fuel 2015; 150: 226-235. http://doi.org/10.1016/j.fuel.2015.01.087.

[55] Xiao Z, Ladommatos N, Zhao H. The effect of aromatic hydrocarbońs and oxygenates on diesel engine emissions. Proceedings of the Institution of Mechanical Engineers, Ptart D Journal of Automobile Engineering 2000; 214: $307-332$. http://doi.org/10.1243/0954407001527448.

[56] Sung Y, Jung G, Park J, Choi B, Lim MT. Relation between Particulate Emissions and Exhaust Smoke Level in Premixed Charge Compression Ignition Engine. Journal of Mechanical Science and Technology 2014; 28(2): $783-787$. http://doi.org/10.1007/s12206-013-1144-1.

[57] Ovaska T, Niemi S, Sirviö K, Heikkilä S, Portin K, Asplund T. Effect of Alternative Liquid Fuels on the Exhaust Particle Size Distributions of a Medium-Speed Diesel Engine. Energies 2019; 12(11). http://doi.org/10.3390/en12112050.

[58] Ovaska T, Niemi S, Sirviö K, Nilsson O, Portin K, Asplund T. Effects of Alternative Marine Diesel Fuels on the Exhaust Particle Size Distributions of an Off-Road Diesel Engine. Applied Thermal Engineering 2019; 150: 1168-1176. http://doi.org/10.1016/j.applthermaleng.2019.01.090.

[59] Gebremariam SN, Marchetti JM. Economics of biodiesel production: Review. Energy Conversion and Management 2018; 168: 74-84. http://doi.org/10.1016/j.enconman.2018.05.002.

[60] Riedewald F, Sousa-Gallagher M, Technological and economical feasibility of a 40,000 t/y tyre pyrolysis plant: results of a H2020 SME Phase 1 study.conference: European Tyre Recycling Asscociation, 18th March 2016, Brussels. Available on: http://crlltd.com/wp-content/uploads/2016/05/09-Tyre-presentation-ETRA-2016.pdf 


\section{Highlights:}

1. Tire pyrolytic oil and its tailor-made blends with diesel and rapeseed oil examined

2. Best ternary fuel samples subjected to test-bench runs on a modern CRDI engine

3. Efficiency end emission factors determined and assessed w.r.t. measurement accuracy

4. Slight deterioration of efficiency and emission w.r.t. diesel baseline

5. Superior performance w.r.t. RME-based biofuels 